\title{
BILDIRI METNi
}

\section{Türkiye Kentleşmesinin Çok Boyutlu Sürdürülemezliğinde Yeni Bir Yol Arayışı: Orta Ölçekli Kentler Üzerinden Kır-Kent Dayanışma Ağları}

\author{
In Search of a New Approach for Multidimensional Unsustainability of \\ Turkey's Urbanisation: Rural-Urban Solidarity Networks on the Basis of \\ Medium-Sized Cities
}

\author{
Çare Olgun Çalışkan, ${ }^{1}$ Azime Tezer ${ }^{2}$ \\ ${ }^{1}$ Mimar Sinan Güzel Sanatlar Üniversitesi, İstanbul \\ ${ }^{2}$ İstanbul Teknik Üniversitesi, İstanbul
}

\section{ÖZ}

Türkiye kentleşmesinin, sadece nüfus hareketleri ve yerleşimlerin büyüklük ve yayılma etkileri bakımından değil, toplumsal, ekolojik, ekonomi-politik ve kır-kent ilişkilerine dair sorunlar içeren ve devam etmesi halinde mevcut durumu daha da çözümsüz kılacak bir gidişatı söz konusudur. Hızlı büyümeye çalışan ve neoliberal kentleşme politikalarının baskınlığına sınırlı ve yetersiz müdahalesiyle devletin de göz yumduğu bu sürdürülemez kentleşme eğilimi, gelişmekte olan ülkeler kadar dünya geneli için de benzerlikler taşırken farklı çözüm arayışlarını da beraberinde getirmektedir. Yakın gelecekte kentlerin niteliksel ve niceliksel baskı ve yayılmasının süreceği ve bu gidişata dayaIı artan nüfusu en çok barındıracağı öngörülen yerleşme türü olan orta ölçekli kentlerinse (OÖK) önerilecek yeni kentleşme yaklaşımları içinde özel ve öncelikli bir yere sahip olması gerekmektedir. Şimdiye kadar nüfus ve temel sosyo-ekonomik gelişme ekseni dışında ele alınmayan OÖK, ülkemizdeki sürdürülemez kentleşme seyri için farklı potansiyeller, nitelikler ve ilişkiler üzerinden çözüm yaklaşımının temelini oluşturabilecektir. Türkiye kentleşmesinin sürdürülemezliğinde, yeni bir yol arayışı için OÖK'yi odağına alan bu çalışma bu bakımdan OÖK'nin hangi niteliksel boyutlar ile ele alındığında kentleşme-

\begin{abstract}
The maintenance of urbanisation in Turkey appears to be on a trend whereby it will lead to further lack of solution in the existing situation not only by reason of its effect in terms of magnitude and dispersion on population movements and settlements, but on the basis of its multidimensional nature including social, ecological, economic-politic and rural-urban associations. This unsustainable trend of urbanisation stems from the domination of neoliberal urbanisation policies aiming at rapid development which the state turns a blind eye to by extending merely limited and insufficient interventions in response. Such a trend bears similarities in developing countries notably including Turkey and around the world and brings along with it necessities for varying solutions. The qualitative and quantitative domination of urban spaces is prescribed to continue to disperse itself in near future with small-sized cities pointed out as the type of settlement to accommodate the population increase arising from such a trend. Such settlements will thus be positioned as a special and prioritised element in suggestions for new approaches to urbanisation. Medium-sized cities have not been discussed outside the axes of population and basic socioeconomic development so far. However, these cities may constitute the main axis of a significant approach focusing on solutions on the basis of different potentials, characteristics, and linkages for the unsustainable course of urbanisation observed in Turkey. The present study concentrates on small-sized cities as a means to find a new pathway in the midst
\end{abstract}

Bu makale, Çare Olgun Çalışkan'ın ITÜ Şehir ve Bölge Planlama Bölümü’nde sürdürdüğü “Türkiye Kentleşmesi İçin Yeni Bir Yol Arayışında Orta Ölçekli Kentler Üzerinden Kır-Kent Dayanışma Ağları: Kars-Boğatepe Örneği” başııkı tez çalışması kapsamında hazırlanmıştır. 
de yapıcı/çözümleyici bir rol üstlenebileceğini sorgulamakta ve bu bağlamda OÖK'yi güçlü bir kır-kent ilişkisi, yerel ekonomileri canlandırabilecek, rekabetçilik yerine dayanışmayı koyan ve ağ ilişkilerine dayalı olarak tariflemeye çalışan bir yöntem denemesini içermektedir. Türkiye'de süregelen kentler ve bölgeler arası dengesizlikler, ekolojik kayıplar, kırsalın ve üretim yapılarının azalan değeri ile göç olgusu hala önemini korumaktadır. Mekânsal açıdan çok merkezli gelişim ihtiyaçlarını farklı yönleriyle içeren bu çalışma, bir yanıyla metropolleşen (büyükkentleşen), bir yanıyla da çok yönlü gelişme sorunları yaşayan kentler arasında denge unsuru olarak OÖK'yi görmekte ve bu kentler üzerinden kır-kent dayanışma ağlarının teorik-kavramsal bir arka plan üzerinden genişletilmiş okumasını yaparak Türkiye için görece özgün bir OÖK tanımı ortaya koymayı amaçlamaktadır. Çalışmanın sonunda, OÖK'yi kır-kent ilişkisi ve dayanışma ağları bakımından tanımlamak için belirli adımlardan oluşan çok değişkenli bir yöntem uygulanmış, ulusal ölçekte istenilen düzeyde veri temini ve analizi yapılamamış olsa da belirli ön bulgulara ve ileriye dönük olarak çalışmanın geliştirilmesine yardımcı olacak değerlendirmelere ulaşılmıştır. Bu çalışma, gerek kentleşmede OÖK'nin yeri ve önemini gerekse taşıyacağı niteliklerin türü ve temsilinin ne denli gerekli ve bir o kadar da zor olduğunu ortaya koyması bakımından son derece önemlidir.

Anahtar sözcükler: Ağlar; dayanışma; kentleşme; kır-kent ilişkisi; orta ölçekli kentler.

\section{Giriş}

Dünya kentleşmesinin nüfus ve yerleşim büyüklükleri bakımından bugünü ve yakın gelecekteki seyri, Türkiye gibi gelişmekte olan ülkelerin kentleşmeleri bakımından önemli tespit ve öngörüler içermektedir. 1980'den itibaren gözle görülür bir artış eğilimi gösteren dünya kentsel nüfusu 2007'de ilk kez kırsal nüfus oranını aşmış (data.worldbank.org) ve günümüzde \%55'e ulaşarak 4 milyarın üzerine çıkmıştır (UN, 20I6a). Dünya kırsal nüfusuysa, 1980'li yıllardan bu yana oranını \% I6 kaybederek 3.4 milyara ulaşırken Türkiye ve Latin Amerika ülkeleri gibi hızla gelişen/kentleşen ülkelerde en büyük kayıpları vermiştir (data.worldbank.org). 2050'de yaklaşık 10 milyarı bulacağı tahmin edilen dünya nüfusundaki artışa neredeyse bütünüyle kentlerin katkıda bulunacağı öngörülürken (Davis, 20।0; UN, 20l4b), kırsal nüfusun artışını durdurmaya başlayacağı; 2020'de en yüksek seviyesine ulaşıp bunun ardından düşüşe geçerek 2050'de 3.2 milyar olması beklenmektedir (UN, 20|4a). Yerleşim büyüklükleri açısından bakıldığındaysa, yakın gelecekte hızlı büyüme gösteren kentsel yerleşimlerin, bugün dünya kentsel nüfusunun yaklaşık \%60'ını barındıran ve nüfusu I milyondan az olan orta ve küçük ölçekli kentler olacağı öngörülmektedir (UN, 20l6a; UN, 20l4c). Bugün, neredeyse dünyadaki kentsel nüfusun yarısı (dünya nüfusunun da \%26.8'i) nüfusu 500.000'i geçmeyen kentlerde yaşamaktadır. of the unsustainability of urbanisation in Turkey and moves on to question the qualitative dimensions to be utilised in deliberations concerning medium-sized cities with a view to allowing them to assume a constructive/solution-oriented role in this respect. The study thus represents an attempt at a methodology that replaces competition with solidarity and endeavours to establish such solidarity on the basis of network-specific linkages. In addition, the present study addresses the long-established imbalances between cities and regions, ecological losses, the central position assumed by rural spaces and production structures at decreasing values in the phenomenon of migration, and the needs for spatially polycentric development in Turkey by attaching to them the respective level of gravity. In this framework, the study aims to establish a relatively genuine definition for medium-sized cities to be applied in Turkey by offering a wide-scale interpretation for the networks of solidarity between rural and urban spaces through these cities on the basis of a theoretical-conceptual background. The final part of the study applied a multivariate methodology comprised of specific steps to define medium-sized cities in terms of the rural-urban linkage and networks of solidarity and even though the desired level of data acquisition and analysis could not be achieved at the national scale, the study was able to obtain specific preliminary findings and further deliberations that will assist in the prospective development of the study. The present study is of great significance in that it establishes the importance of medium-sized cities in urbanisation and the absolute need for and respective difficulty of determining the type and characteristics to be attained in such cities.

Keywords: Medium-sized cities; networks; rural-urban linkages; solidarity; urbanization.

2050 yılına doğru yaşanacak nüfus artışının \%95'inin gelişmekte olan ülkelerin kentsel bölgelerinde gerçekleşeceği beklenmektedir (Davis, 20 I0). 2030 yılı için gelişmekte olan ülkelerin kent nüfusunun 2 katına, kullanılan kentsel arazi miktarınınsa 3 katına çıkması beklenirken (UN, 20I6b), dünya genelindeki kentleşmenin nüfus ve yerleşim alanları bakımından izlediği seyrin sürdürülemeyeceği açıkça ifade edilmektedir (Reader, 2007; UN, 2016b). Söz konusu kentleşme seyrinin 21. yüzyılla birlikte ekoloji, metropolleşme, kır-kent ilişkileri, tarımsal üretim gibi alanlarda giderek artan endişeleri de beraberinde getirdiği ve ülkeleri yeni çözüm arayışlarına ittiği bilinmektedir. Türkiye gibi gelişmekte olan ülkelerin kentleşme süreçlerinde daha da belirleyici hale gelen 'metropolleşme' konusunda Mumford'un 'büyüme' ve 'çöküş' üzerine temellenen tezinden esinlenen değerlendirmeler, metropoliten gelişim doruk noktaya ulaştığında; sorunları çözülüp, gelişme doğru yönlendirilmediğinde çöküşün kaçınılmaz olacağını vurgulamaktadır (Çabuk ve Demir, 20।0). $\mathrm{Bu}$ bağlamda hızlı kentleşen, kırsal gücünü belirli oranda koruyabilmiş ve kentleşmenin olumsuz etkilerini giderek daha fazla hisseden Türkiye'de kentleşmeye dayalı yaklaşımlara yön verebilecek temel çıkarımlar arasında öne çıkan konular, özetle kentsel alanlarda artmaya devam edecek nüfus, kır üzerindeki kentleşme baskısı ve buna bağlı kayıpların artışı ile kentsel denge arayışlarında alt metropoliten yerleşmelerin (başta orta ölçekli kentlerin) artan önemi olarak sıralanabilir. 
Türkiye'nin kentleşme sürecine nüfusun kentsel alanlardaki birikim süreci ötesinde bakıldığında; kentleşmenin, ekonomi-politik, toplum-mekan ilişkisi, ekolojik etki ve özellikle de kırsal yapı ve kır-kent ilişkisi bakımından çok boyutlu sorunlar içerdiği ve bunların kentleşmeye dayalı çözüm yaklaşımlarını belirlemede önemli etkileri olduğu söylenebilir. Ekonomi-politik yönüyle irdelendiğinde, dünya kapitalizmi ile bütünleşmeyi sürdüren Türkiye kentleşmesi, mekânın yeniden üretimi, kentsel boş arazilerin giderek azalması ve neoliberal politikalar gereği yeniden işlevlendirilmesi gereken alanlar nedeniyle büyük ölçüde mekânsal dönüşüm süreçleriyle şekillenmekte (Çalışkan vd, 20I3) ve bu durum özellikle metropollerde yoğun olarak karşımıza çıkmaktadır. Ülkemizde nüfus ile kapitalin ülke mekanındaki dağılımının piyasa süreçleri ile belirleniyor olması, kendini 'mekansal eşitsiz büyüme' ile ortaya koyarken (Tekeli., 2006), bir yanda metropolleşen diğer yandaysa göç ve sosyo-ekonomik gelişme sorunları artan kentleri ortaya çıkarmaktadır. Türkiye kentlerinin neredeyse tamamında küreselleşmenin yarattı̆̆ değişim ve benzeşme süreçlerinin izlenebileceğini belirten Kiper (2007), üretim özelliklerini yitiren kentlerin birer tüketim merkezine dönüşerek birbirine daha çok benzeyen mekânsal yapılarıyla kimliksizleştiğini ifade etmektedir. Tekeli'nin yarışan yerellikler olarak tanımladığı bu süreçte yerel yönetimler, sermayenin desteklenmesine yönelik bir müdahale anlayışına yönelirken (2006); belediyelerin başarısı artık sağladığı kamu hizmetinin niteliğiyle değil, yöresine çekeceği yatırımın miktarı ve karlılı̆ı ile ölçülür hale gelmiştir (Kiper, 2007).

Toplum-mekan ilişkisi yönüyle bakıldığındaysa, Türkiye kentleşme süreci boyunca bu ilişkinin başarılı analiz edilemediği ve kentleşmeye, -nüfus odaklı- engellenebilir bir yer değiştirme olarak bakan yüzeysel yaklaşımların ağırlıklı olduğu görülmektedir (Tekeli, 20II). Bugünse Türkiye kentleşmesinin genelde ekonomik ve mekana dayalı eylem ve sonuçlarla belirlendiği, toplumsal yapı dinamiklerinin sonucu etkileyecek düzeyde genel bir bileşen olarak görülmediği (Çavuşoğlu, 2017); toplumsallı̆̆ın, devletin gücü ile sermayenin dönüştürücü etkisi altında edilgen bir konuma itildiği görülmektedir (Altınok ve Enlil, 20I2). Türkiye kentleşme süreci beraberinde psikolojik açıdan farklı hoşnutsuzluklar da yaratırken bunun ardında değişen gündelik yaşam pratikleri, kırsaldan ayrışma, kentsel mekanın büyüklüğü ve kalabalık hali gibi etmenler yatmaktadır (Sevinç, 2012). Ülkemizde, insanların yaşam memnuniyetine ilişkin araştırmaların küçük ve OÖK’leri öne çıkarması bu tespitin dolaylı bir yansıması olarak okunabilir (TÜiK, 20I3). Ostrom'un, metropolden küçük ölçekli yerleşimlere doğru gidildikçe işbirliği, kolektif eylem gücü yaratma ve katılımlı sonuç elde etmenin kolaylaştığını ortaya koyması da (Ostrom'dan aktaran Harvey, 2013) bu açıdan önemlidir. Öte yandan özellikle son 10 yılda dünyanın birçok yerinde toplumlar, yaşam alanlarının değişimi, gelişimi ve dönüşümü ile ilgili kararların kendi iradelerine rağmen dayatılmasına karşı tepkilerini daha görünür biçimde ortaya koymakta ve kentleşme süreçlerinin bir eyleyicisi/paydaşı olduklarını göstermektedirler (Çavuşoğlu, 2017).
Türkiye'de kentleşme-ekolojik yapı ilişkisine bakıldığında, 1990'lı yıllarla birlikte ekolojiye dair kaygıların arttığı ve kirlenmeye yol açan etmenlerin başında kentleşmenin gösterilmeye başladığı görülürken metropoller ekolojik sorunların yoğunluk kazandığı bölgeler olmuşlardır (Tokuçuoğlu, 1993). 2000'li yıllarsa, hızlı kentleşen ülkemizde ekolojik dengelerin bozulduğu, kırsal ve doğal çevrelerdeki kentleşme ve yatırım baskılarının arttığı ve bu süreci kontrol altına alacak bir kamu politikasının geliştirilemediği bir süreci öne çıkarmıştır (DPT, 2007). Yoğun göç ve kentleşme sonucu ekolojik eşikleri baskı altındaki kentlere odaklanan Çavuşoğlu (20I7), son yıllarda yapılan yasal düzenlemelerle kırsal alanlar, ormanlar, tarım alanları, meralar ve su kaynaklarının alım-satım ve kar amaçlı projelere konu edilebilmesiyle, kentsel ya da kırsal alanda metalaşmamış hiçbir bölgenin kalmadığının altını çizmektedir. Türkiye'nin son dönem yapılaşma sürecini ele alan Karabey de (20I4), gelecek kuşaklar için doğanın kendini yenileyebileceği rezerv alanlar bırakmayan kentleşme süreçlerinin kalkınmacı ve modernleşmeci amaçlarla, tarih bilincini ve bilimsel bilgiyi yadsıyarak yapılageldiğini vurgulamıştır. Yakın gelecekte, iklim değişikliğine bağlı olarak dünyanın birçok yerinde kentsel alanların kırsal ekosistem servislerine daha yoğun bir biçimde bağımlı kalacağı bilinmekteyken (Leeuwen, 20I5), Türkiye'de kentleşmenin bir kalkınma aracı olarak görülmesi, giderek üretim alanı ve ilişkilerinin değişmesine, dışa bağımlılığın artmasına -dolayısıyla beslenme alanlarının kaybolmasına- neden olduğundan kentleşmenin gerekliliğini sorgulayan eleştirilere konu olmaktadır (Güney ve Selçuk, 20I2).

Kırsal yapı ve kır-kent ilişkilerine bakıldığında, güçlü potansiyeller içeren dünyadaki sayılı bölgeden biri olan Türkiye'de kentleşmenin geleceği kritik önem taşımaktadır. Son dönemde Avrupa'da kırsal kalkınma politikaları için potansiyel bir araç olarak değerlendirilen kır-kent ilişkileri, kentsel alanların kırsal hinterlantlarıyla olan ilişkileri bakımından da önem kazanmaktadır (Copus, 2015). Artık geçmişte olduğu gibi kesin bir kır-kent ayrımından söz edilemeyeceği iddia edilse de (Tekeli, 20I I-2016; Harvey, 2013; Lefebvre, 1970), Türkiye deneyiminin bu iddiayı tam olarak karşılamadı̆ı söylenebilir (Yoloğlu, 2017; İrdem ve Mutlu, 2016). Güncel kentleşme tartışmaları, kenti ve kırı yeni bir yerleşmeler sistemi ve kavramsal yaklaşım içinde ele almayı gerekli görürken (Tekeli, 2016), kent ve kırı birbirinden ayıran istihdam yapıları da önemli değişikliklere uğramakta (Öğdül, 20I0) ve tarım yeniden kent gündemi içine girebilmektedir (Tekeli, 2016). 1980'den buyana uygulanan tarım politikalarının temelde üretici ile devlet arasındaki bağları koparan, çiftçi örgütlülüğünü zayıflatan, şirketlerin tarımda egemen olmasına zemin hazırlayan ve hem tarımsal üretim ve rezerv alanlarının azalmasına yol açan, hem de ekosistem dengesini bozucu mekan politikalarını yaygın hale getiren bir süreç yarattı̆̆ı söylenebilir (Aysu, 20I3). Endüstriyel gelişme ya da yayılmacı kentleşme politikaları sonucu tarımsal üretim alanlarında görülen fonksiyonel dönüşümler son yıllarda en sık 
gelişmekte olan ülkelerde yaşanırken (Azadi ve Ho, 20 I I; Kraus, 20I3), bu dönüşümlerde en fazla payı olan etkense, kentsel nüfus artışıdır (Azadi ve Ho, 20I I). 2000'li yıllarla birlikte artık kendi kendine yetebilen tarım ülkesi imajını kaybeden, dışa bağımlılı̆ı artan bir Türkiye'den söz edilmeye başlanmıştır (Güney ve Selçuk, 20I2). Öte yandan 2012 ve 2013 yıllarında yapılan idari düzenlemelerle ülkemizdeki kent ve kır yerleşimlerine dair alansal ve nüfusa dayalı dağılım dengesi değişmiş, bu düzenleme öncesi \%23 olan kırsal nüfus oranı \%8,7'ye (günümüzde \%7.7'ye) kadar düşmüş (TÜiK, 1927-2000 ve TÜiK, 2007-20I7) ve kırsalın temsil gücü önemli ölçüde azalmıştır. Oysaki Türkiye'nin, ilçeler düzeyinde \%45'inin kırsallığı baskın, \%38'inin geçiş bölgesi ve sadece \%।7'sinin kentselliği baskın özellikler gösterdiği; geçiş bölgelerinin yüksek oranınınsa kentsel ve kırsal yapıların geçirdiği değişimi gösterdiği bilinmektedir (Öğdül, 2010). Bu bağlamda bir yanıyla güç ve nüfus kaybına uğrayan kırsal alanlar diğer yandan büyük kentlerden daha küçük ölçekli yerleşimlere yönelen bir tersine göç eğilimine de konu olmaktadırlar. Bu göçler, kent-kır ilişkileri kadar kırdaki değişimi de yansıtırken, kırsal-geleneksel yapıyı kısmen de olsa dönüştürmektedir (Gıda Tarım ve HayvancıIık Bakanlığı vd., Ulusal Kırsal Kalkınma Stratejisi 20I4-2020, 20।4). Son yıllarda kırsal alandaki tarım ve doğa kaynaklı yerel girişimciliğin artması da değişen bu göç eğilimlerinde etkili olabilmektedir. Kentlerde tüketicilerin sağlıklı ve doğal gıdaya yönelik artan kaygıları ve üreticilerin serbest piyasada (çok aktörlü geleneksel gıda zincirinde) düşük gelir payına sahip olması, tarıma dayalı yerel girişimciliğin büyümesindeki başlıca etkenlerdir (Yaşlak, 20I6). Bir nevi aracısız bir yerel ekonomi anlamı taşıyan ve doğal üretim süreçlerini içeren söz konusu kırsal girişimciliğin (Jarosz'dan aktaran Yaşlak, 2016), başta internet kullanımı ve ilerleyen teknolojik imkanların da etkisiyle uzak mesafeli ekonomiler yaratabildiği ve kır-kent ilişkilerine yeni bir boyut kazandırdığı söylenebilir. Ancak günümüzde mekânsal kutuplaşmalar gelişmiş bölgeler lehine güçlenme, eşitsizlikler artma, sosyal bütünleşme de zayıflama eğilimi gösterirken, ana göç eğilimlerinin önemli oranda değişmemesiyle birlikte nüfus belirli şehirlerde toplanarak bu yerleşmelerin çekim güçlerini arttırmaktadır (Kalkınma Bakanlığı, Türkiye Bölgesel Gelişme Ulusal Stratejisi-20l4-2023, 20I5). Ülkemizde gelişmişlik düzeyi ile göç arasındaki güçlü korelasyon (gelişmişlik düzeyi düşük seviyeden yüksek seviyeye gittikçe göç eğiliminin azalması) varlığını sürdürmekte ve ekonomik nedenler hala en önemli göç nedenlerini oluşturmaktadır (Yakar, 20I3; Şen, 2014). Aynı zamanda iç göçlerin niteliği zamanla değişmiş, azalan kırsal nüfusun da etkisiyle ağırlıklı göç eğilimi artık kırdan-kente değil, kentten kente doğru olmuştur (Şen, 20|4). Bu durum ülke bütününde kentsel ve bölgesel denge arayışlarını da güçleştirmektedir.

Farklı boyutlarıyla bakıldığında Türkiye kentleşmesinin izlediği süreç ve uygulamalara yön veren eğilimlerin hem günümüz hem de yakın gelecek için sürdürülemez olduğu ve kentler arası dengesizlikleri arttırarak, çözüm yaklaşımlarını daha da zorlaştırdığı açıkça görülmektedir. Bir yandan hızla-kendine özgü (nüfus birikimi ve siyasi kararlarla) metropolleşen, diğer yandan da bütüncül politikaların uygulanmayışıyla sosyo-ekonomik açıdan geri planda bırakılan kentler sonucu mekânsal bir kutuplaşmaya yol açan bu temel sorun, buradaki çalışmanın çıkış noktasını oluşturmaktadır. Çalışma, kentlerin gelişiminde daha dengeli bir yaklaşımın gerekliliğine odaklanmış ve bu noktada -yakın geleceğin kentleşme öngörülerinde önemi artacak olan- "orta ölçekli kentler" üzerinden nasıl bir çözüm yaklaşımı geliştirilebileceğini irdelemiştir. Bu bağlamda, rekabetçiyereli tüketen bir kentleşme yerine kırsal yapılar ve kır-kent ilişkileri üzerinden -yerel ekonomileri destekleyici- dayanışmacı bir kentleşmeyi; alan/mekan odaklı bir gelişme yerine de ağ ilişkilerini ön plana çıkaracak bir yaklaşımın gerekliliği ortaya koyulmuştur. Bu yaklaşım içinde Türkiye için nasıl bir orta ölçekli kent tanımının uygun olduğu sorusuna yanıt aranan yöntem kısmında demografik ve sosyo-ekonomik nitelikteki ikincil verilerden yararlanılmış ve il bazında karşılaştırmalı analiz tabloları geliştirilmiş ve sonunda il düzeyinde orta ölçekli kentler belirlenmiştir. Çalışmada izlenen adımlar ve yöntemin gerekçeleri ile teorik/kavramsal arka plan ilerleyen bölümlerde detaylandırılmıştır.

\section{Türkiye Kentleşmesi İçin Yeni Bir Yaklaşım Önerisi}

Giddens, devlet ve piyasa mantıklarının hakimiyetindeki kentleşmenin, kentleri yönlendirmede başarısız kalarak, yaşanabilir kentler ve geleceği konusunda belirleyici olabilen yerel topluluklar yerine insancıl olmayan kentler ve yabancılaşmış topluluklar yarattığını ortaya koymaktadır (Giddens'tan aktaran Tekeli, 2006). Küreselleşmiş bir bilgi toplumuna geçişi yaşayan dünyada, yerleşme terminolojisinde yeni bir kavramsallaştırma arayışına girilirken (Tekeli, 2016), kentleşmenin artık gezegensel bir olgu olduğu, kır-kent karşıtlığının ötesinde, kentleşme için yeni bir söz dağarcığına ihtiyaç olduğu savunulmaktadır (Brenner'dan aktaran Cihanger, 20l4). Türkiye'de yerleşme yapısının yeniden tanımlanması için farklı vurgu noktaları olan araştırmalara ihtiyaç olduğunu ileri süren Tekeli'yse ülke mekanındaki eşitsiz gelişime ilişkin yeni uyum süreçleri ve gelişim dinamiklerinin yeni bir açıklayıcı çerçeve kullanılarak irdelenmesini ve bunun, kırsalı da bütüncül olarak içermesi gerekliliğini belirtmiştir (Tekeli, 2006). Dünya genelinde büyük kentler üzerinden şekillenen kentleşme eğilimleri yerine alt metropoliten alanlar ve daha küçük yerleşmeleri odağına alan kentleşme yaklaşımlarının gerekliliği önem kazanmakta$\operatorname{dir}(U N, 2014 c ;$ Davis, 20I0). Türkiye içinse nüfus seyrelmesi nedeniyle kırsal yerleşimlerin ölçek ekonomilerinden uzaklaşması sonucu yaşadığı kayıplar nedeniyle yerel koşulları gözeten yenilikçi yaklaşımların geliştirilmesi bir zorunluluk halini almıştır (Gıda Tarım ve Hayvancılık Bakanlığı vd., Ulusal Kırsal Kalkınma Stratejisi 20I4-2020, 20I4). Konuya yerleşmeler sis- 
temi üzerinden yaklaşan Çabuk ve Demir (2010), gelişebilme potansiyeline sahip orta büyüklükte kentlerin özellikle desteklenmesi gerektiğini, desteklenecek kentlerin orta ve yavaş gelişen bölgelerden seçilerek nüfusun dengeli dağılımına katkı yapabileceğini, bunun için nüfusun mekansal dağıımının kırsal ve kentsel stratejilerin kombinasyonunu içermesi gerektiğini ileri sürmektedir. Sonuçta Türkiye kentleşmesi için farklı kavramsalıklar da içeren yeni çözüm yaklaşımlarına yönelik ihtiyaç son derece açıktır. Çalışma, bu bakımdan -önceki bölümde aktarılan- kentleşmenin tüm boyutlarını kapsayacak bir çözüm yaklaşımı geliştirme iddiası taşımazken, öncelikli görülen ve dolayı (çarpan) etkileri ile kapsayııı bir çözümü hızlandırması beklenen bir çerçeve ortaya koymayı amaçlamıştır. Kentleşmenin yerleşim büyüklükleri ve nüfus hareketleri bakımından yakın geleceğinde önemi tüm dünyada artmaya devam edecek olan OÖK'ler üzerinden temellendirilen bu yaklaşımda metropolleşme ekseninden uzaklaşan, yerleşmeler arası dengeyi gözeten, kırsal yapı ve ilişkileri daha çok içeren (dolayısıyla ekolojik açıdan daha sürdürülebilir), göç tutma kapasitesi yaratabilen bütüncül bir nitelik arayışı ortaya koyulmaya çalışılmaktadır. Bu noktada yerel ekonomilerin de kırsal yaşamın gelişmesini destekleyecek etkiler yaratabilmesi için dayanışma ve ağ ilişkileri ile bir arada düşünülmesi gerekmektedir. Özellikle kentsel alanlarda giderek artan sağlıklı-doğal gıda talebi ile ekolojik açıdan temiz bir çevrenin avantajlarıdan yararlanma isteği kırsal ekonomiler için önemlidir. OÖK'leri odağına alan planlama ve kentleşme konulu literatür birikimi, 40 yıla yayılan ve $2000^{\prime}$ 'li yıllarla birlikte önemi artan bir gelişim izlerken (Şekil I), üzerinde ortaklaşılan bir OÖK tanımından bugün bile söz edilememektedir.

OÖK'ler artık çok yönlü ele alınan, mekansal bir gözlem birimi olmaya başlamış ve çoğunlukla nüfus aralıklarına göre, kısmen de farklı sosyo-ekonomik, demografik vb. değişkenlerden yararlanılarak belirlenmektedir. Bu konuda geniş kapsamlı analiz ve çaıışmaların yoğunlaştığı ülkeleri barındıran $A B$ ile birlikte $O E C D$ ve UN'nin belirlediği OÖK kabulleri, çok sayıda akademik çalı̧mada referans olarak gösterilmektedir. Ancak hem uluslararası alanda hem de Türkiye özelinde yerleşmelerin ölçek ve nüfus kabullerindeki farkllıklar bu konuda esnek bir analiz zemini yaratırken (Tablo I), aynı zamanda bölgesel düzeyde (Kuzey Amerika, Latin Amerika, Avrupa, Uzakdoğu vb.) ortaklaşabilen OÖK yaklaşım ve kabullerinin olmadı̆̆ııı göstermektedir.

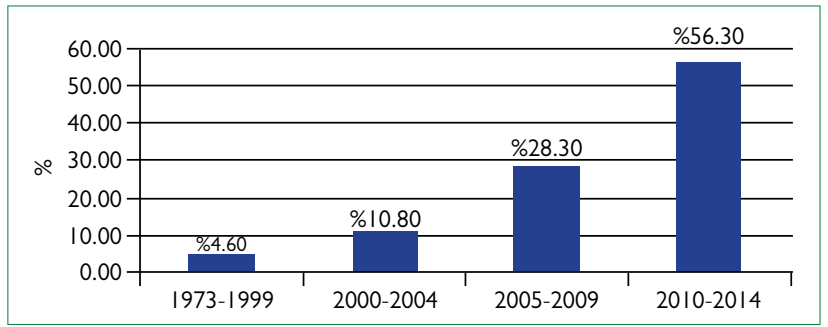

Şekil I. OÖK'e dayalı yapılan uluslararası literatür araştırmasında elde edilen tüm elektronik veri tabanı ve internet erişimli akademik bildiri/makale tarama sonuçları.
Ülkemizde 1980'li yıllarla birlikte metropolleşme eğilimlerine odaklanan çalışmalarda yerleşme kademelenmesinin bir ayağı olarak gösterilen OÖK'ler, 2000 'li yıllarla birlikte, kentleşme alanındaki çalışmalarda, üzerine odaklanılan yerleşim alanları olmaya başlamıştır. Gelişmekte olan ülkelerde planlama, büyük metropoliten alanların problemlerine odaklı-ayrıcalıklı ilerlemiş olsa da küçük ve orta büyüklükteki şehirlerin potansiyellerini harekete geçirebilirse, bu ülkeler için yeni kentleşme gündemleri oluşturulabilecektir (UN, 20I6b). Örneğin, OÖK'ler, İstanbul Çevre Düzeni Planı'nda (IBB, 2009) kentleşme sorunlarına çözüm odaklı geliştirilen politikalara da konu olmuş ve ara kademe-kentsel çekim merkezleri olarak ele alınmıştır. Planda (IBB, 2009), ulaşım ve iletişim teknolojisindeki gelişmeler doğrultusunda OÖK'lerin sayı ve etkinliğinin arttığı takdirde kır-kent arası kutuplaşmaların, hakim göç eğilimlerinin önüne geçilebileceği ve aşırı yük üstlenen metropollerin yükünün hafifleyebileceği ileri sürülmüştür. Nitekim Türkiye'deki göç hareketleri incelendiğinde, bölgesel düzeyde verilen göçün düşük ya da yüksek oranda oluşu, komşu bölgelerdeki göç eğilimlerini de paralel yönde etkilediğinden (Tatlı, 2016), kentler arasındaki (kırsal etkileri de içeren) göç nedenlerini azaltııı denge politikalarının gerekliliği özellikle de küçük ve orta ölçekli kentler bakımından son derece önemlidir (Tatı, 2016; Özyakışır, 2012). Yerleşme sistemi içinde OÖK'lere odaklanan Yazar ise (2006) metropolleşme eğilimlerine karşı OÖK gelişimini ikincil merkez yerleşmeler olarak ekonomi ve pazar alanında öne çıkarmayı gerekli görürken, OÖK'lerin kırsal ve kentsel gelişim bütünlüğü içinde ele alınmasını vurgulamaktadır. Yazar’a koşut nitelikteki yerleşim sistemi-nüfus ilişkisine odaklanan çalışmalarında Çabuk ve Demir'se (20I0), Türkiye'nin metropolleşme deneyiminin bugün yaşandığı gibi gelecekte de kırsal ve diğer kentsel yerleşme türleri (küçük ve orta büyüklükte kentler) için olumsuz etkileri olacağııı ortaya koymuşlardır. Çalışmaları, dengeli gelişimin temel mekansal araçlarından biri olarak görülen OÖK'lerin geliştirilmesi yaklaşımının Türkiye'de başarılı olamadığını; mevcut bölgesel ve kentsel politikalar devam ettirildiği takdirde, küçük-orta ölçekli yerleşimlerde gerileme eğiliminin giderek artacağını göstermiştir (A.g.e., s.2।2).

Tablo I. Türkiye'de ve uluslararası alanda OÖK için nüfus aralığı kabulleri

\section{Nüfüs Aralıkları}

\begin{tabular}{ll}
\hline $\mathrm{OECD}^{\left[{ }^{[1]}\right.}$ & $200.000-500.000$ (Kentsel nüfus) \\
$\mathrm{AB}^{\left[{ }^{2]}\right.}$ & $300.000-1.000 .000$ (Toplam nüfus) \\
$\mathrm{BM}^{[3]}$ & $1.000 .000-5.000 .000$ (Toplam nüfus) \\
Türkiye $^{[4]}$ & $100.000-750.000$ (Toplam nüfus) \\
& $50.000-500.000$ (Kentsel nüfus) \\
\hline
\end{tabular}

Kaynak: ${ }^{[l]}$ https://data.oecd.org/popregion/urban-population-by-citysize.htm. ${ }^{[2]}$ www.smart-cities.eu. ${ }^{[3]}$ World Urbanization Prospects, UN, 20I4. ${ }^{[4]}$ https://tez.yok.gov.tr/UlusalTezMerkezi. 
Uluslararası literatürde daha çeşitli boyutlarıyla ele alınan OÖK'ler genel anlamda dengeli bir mekânsal gelişimin sürdürülebilmesi bakımından öne çıkarılmaktadır. Bu bağlamda OÖK'lerin metropollerden daha bütünleyici kent-kır etkileşimine sahip olduklarını belirten Bolay ve Rabinovich (2004), OÖK'lerin kırsaldan daha modern bir yaşam ve istihdam sunumuyla ayrıştığını; metropollerden de yine daha kaliteli bir yaşam ve daha sağlıklı bir çevre ve bazen de mikroekonomi fırsatları sunumuyla nüfus akışları sağlayabildiğini ileri sürmektedir. Sassen ise (20I2) artık çoğu firmanın özellikle gelişmiş ülkelerdeki pahalı ve rekabetçi kentler yerine OÖK'lere yerleşmeyi tercih ettiklerini ve bu kentleri içinde bulunduğumuz dönemin yükselen değerleri olarak görmemiz gerektiğini ileri sürmektedir. OÖK'ler, uzun ömürlü/dayanıkIı birer kent olma adına daha sürdürülebilir bir büyüme sağlayabilmeleri nedeniyle sık sık büyük bir metropolün kıymetli bir temsilcisi olarak değerlendirilirken (Léo vd, 2009), kompakt karakterleri onlara daha iyi yaşam koşulları (ulaşımda harcanan süre ve trafik sıkışıklığı, sera gazı salımı, etkin kamu yönetimi vb) sağlama bakımından güç kazandırmaktadır (Laigle, 2007; Akt. Léo vd., 2009).

Çalışma, önerdiği çözüm yaklaşımında önemi tüm dünyada açıç̧a ortaya koyulan OÖK’lere dayalı iki temel boyuta odaklanmaktadır. Geleceğin kentleşme süreci ve etkileri hesaba katıldığında Türkiye özelinde öncelikli görülen kır-kent ilişkisizliği ve kentlerin baskın/öncü rolleriyle şekillenen kentleşme sürecini değiştirebilmek, dolayısıyla ekolojik açıdan da daha sürdürülebilir bir süreç yaratabilmek amacıyla kır-kent ilişkisi çözüm yaklaşımının ilk boyutunu oluşturmaktadır. Çözüm yaklaşımının 2. boyutu ise OÖK'ler üzerinden belirli bir gelişme/canlandırma süreci oluşturabilmek için özellikle de kırsalda yerel ekonomileri dikkate alan, yerleşmeler arasında geliştirilmesi gerekli görülen dayanışma ve ağ ilişkileridir.

\section{Orta Ölçekli Kentleri Kır-Kent İlişkisi, Dayanışma ve Ağlar Üzerinden Değerlendirme}

Çalışmada orta ölçekli kentler üzerinden güçlü bir kır-kent ilişki potansiyeli ve kırsallık yanında -yerel ekonomilerin gelişimi bakımından- dayanışmacı ve ağ ilişkilerine dayalı bir nitelik arayışına gidilmiş ve OÖK'leri bu bağlamda hangi değişkenlerin temsil edebileceği konusunda bir literatür değerlendirmesi yapılmıştır. Günümüz bulgularının orta ve küçük ölçekli kentleri kırsal dönüşümde, kırsalla olan ilişkileri nedeniyle çok önemli bir role sahip göstermeleri (Johnson vd., 20l6), kentleşme yaklaşımları bakımından son derece önemli ve yol göstericidir. OÖK'ler, kır-kent ilişkisinde barındırdıkları kır hinterlantları bakımından öne çıkarken kırsal karakterli ve görece az gelişmiş kentlere göre daha yüksek, metropollere göreyse daha düşük nitelikte kentsel özellikler taşıyan yerleşimler olarak değerlendirilmektedir. Ülkelerin sosyo-ekonomik gelişmesi bağlamında daha sürdürülebilir bir kentleşmeyi ve beraberinde daha sağılılı bir kır-kent ilişkisini sağlayabilmek için OÖK'lerin gelişimini gerektiren nedenler özetle şu şekilde sıralanabilir (Živanović vd, 2014):

- OÖK'ler belirli oranda nüfusu tutabildiklerinden, büyük kentlere yönelen göçü azaltarak metropoller üzerindeki nüfus baskısını azaltırlar.

- Kırsal ve kentsel alanlar arasındaki bağlantıları sağlayan OÖK’ler, kırsal alanlarda tarım dışı faaliyetleri geliştirerek kırsal ekonomilerin iyileşmesini sağlarlar.

- Sağlayacağı dağınık nüfus yoğunluğu deseniyle ülke ölçeğinde bir bütünleşme ortamı oluştururlar.

- OÖK'lerin geliştirilmesiyle dengeli bir bölgesel kalkınmaya geçilebilir.

Kır ve kentin iç içe geçişinin mümkün olabileceği ve buradan hareketle daha sağlıklı kentleşme politikaları üretilebileceğine dair ilginin giderek arttığı günümüzde, küresel politikalar sonucu bozulan kırsal yapıların, yerelleşme ile düzelebileceğini ileri süren Aysu (20I5), kırsal yaşamın beraberinde ekolojik yapıları da düzenleyici etkilerini vurgulayarak özellikle de Türkiye için kırsal yapı-ekoloji ilişkisinin öneminin altını çizmektedir. OÖK'lerin özellikle kır-kent bütünleşmesi ve geri kalmış kırsal coğrafyaların geliştirilebilmesi bakımından daha gelişkin kentler ile kırsal çevre- bölgeler arasında bağlayıcı bir rol üstlenmeleri konusunda öne çıkan yaklaşımlar (Erkut ve Özgen, 20I3), konuya yerleşmeler sistemi ve bütüncül yaklaşımlar açısından eğilmeyi kolaylaştırmaktadır. Bolay ve Rabinovich (2004) ise OÖK'leri, içinde bulundukları bölge, kırsal çevreleri ve diğer kentler ile olan ilişkileri üzerinden değerlendirmenin ve bu bağlamda kentleşme politikası içine oturtmanın önemini vurgulayarak, ağ ilişkileri içinde arabulucu-bütünleştirici niteliklerini ön plana çıkarmışlardır. Özellikle iç göç yapısı bakımından hala süregelen kırdan kente ve ağırlıklı olarak da kentten kente yönelik ekonomik nedenlerle yapılan göçlerin azaltılmasında OÖK'nin kır-kent ilişkisinde taşıyacağı rol son derece önemlidir. Bu açıdan büyük kentlere oranla daha büyük kır hinterlantlarına ve korunabilmiş doğal bir çevreye sahip OÖK'lerin tarıma dayalı ve kırsal ekonomileri geliştirebilme potansiyelinin önemli bir paya sahip olacağı açıktır.

Türkiye'de kır-kent ilişkisi ile doğrudan bağlantılı bir OÖK'leşme yaklaşımı bulunmazken, planlı kalkınma dönemi boyunca da kapsayıcı, kır-kent ilişkisini iyi analiz edebilmiş ve uygulamaya dönüşerek sonuç alınabilmiş bir deneyime rastlanmamaktadır (Kalkınma Bakanlığı, Ulusal Kalkınma Planları, I963-20।4). Türkiye'de kırsal alan yaklaşımları, büyük oranda kalkınmacı bakış açısıyla, nüfus hareketlerini yönetebilmeyi ve kırsal nüfusu kendi yerleşim alanında tutabilmeyi amaçlarken kentleri kollayan bir yapıya yönelmiştir. Artık kırsal gelişme politikalarını içeren yaklaşımların rolü oldukça farklı, küreselleşmenin etkisinde, hızla gelişen teknoloji ve kurumsal yenilikler ile çevresel zorlayıcı faktörlerin belirlediği bir bağlam içinde ele 
alınmaktadır (Byerlee vd., 2009). Bu konuda kır-kent ilişkilerinde tarıma dayalı kırsal faaliyetlere yeni bir paradigmayla bakışın gerektiği yönünde kalkınma ekonomilerinin gündemine giren yeni yaklaşımlar, sektörel-endüstriyel bir bakışın ötesinde, büyüme, yoksulluğun azaltılması, sektörel dengesizliklerin azaltılması, gıda güvenliği ve ekolojik dengelerin sağlanması gibi etkilerle öne çıkarılmaktadır (Byerlee vd., 2009; Janvry, 2010). Bu açıdan salt ekonomik büyümeye önem veren kalkınma iktisadına karşın kırsal boyutu da olan sürdürülebilir bir kalkınma hedefinde girişimciliğin desteklenmesi, ekonomik gelir kaynaklarının çeşitlenmesi, bilgi ve teknolojiye erişimin artması beklenirken yerel bilginin kullanımı ile örgütlenmekooperatifleşme düzeylerinin gelişimi bu hedefi hızlandırankolaylaştıran önemli faktörler olarak değerlendirilmektedir (Gülçubuk, 20I8).

Küresel ekonomik yapı içinde kentlerin kendi rızaları ya da tepeden inmeci politikalar sonucu edindikleri yeni rollerden biri de 'rekabetçilik'tir. Zaman içinde kentler, ekonomik gelişmeyi ve rekabet gücünü arttırmada en önemli mekânsal ölçek olarak görülmeye başlayınca kentlerin rekabetçiliğini ve performanslarını arttırması amacıyla "markalaşma" kavramı da öne çıkarılmıştır (Akturan ve Oğuztimur, 2016). Kamusal yarar-hizmet ve toplumsal hedeflerden uzaklaşılan bu süreçte vatandaşın/kentli kavramının yerini de müşteri almaya başlamıştır (Kiper, 2007). Yarışma, rekabet ve markalaşma gibi konulardaki akademik birikim ve uygulama pratikleri Türkiye'de 2010'dan sonra artmış ve dünyada 30 yılı aşmış olsa da, Gertner, bu alandaki çalışmaların kavramsal bir çerçeveye, test edilebilir modellere ve hipotezlere dayanmadığını; Kavaratzis ise bu alandaki teorik gelişmenin uygulamada netlik kazanamadığını ortaya koymaktadır (Gartner ve Kavaratzis'ten aktaran Akturan ve Oğuztimur, 2016). Rekabete dayalı kapitalist sistem ekonomileri, yarışan ve büyümeye odaklanan bir düzen ortaya koyarak farklı türden zorluklarla mücadeleyi gerektirirken, buna karşı geliştirilebilecek olan alternatif ve daha iyi bir ekonomiyse dayanışmacı yönüyle öne çıkarılabilir (Albert, 2007). Türkiye'de farklı ölçeklerde pek çok kentin, kentsel büyüme sorunları ile karşı karşıya olduğunu belirten Yaşar (20I3), devletin yeniden ölçeklenmesinde önem kazanan yarışmacı kentler söyleminin, bu sorunu daha da derinleştirdiğini ileri sürmektedir. Son dönemde Türkiye genelinde farklı sektörlere dair kentsel proje ve enerji yatırımlarıyla çeşitli turizm türlerinin yarattığı dönüştürücü etkiler, kırsal alanları özgün yerleşim ve üretim yapılarından, kültürel kodlarından uzaklaştırarak rekabete dayalı kentsel tüketim taleplerine bağımlı hale getirmektedir. Rekabetin kırsal kesimde yarattığı etkiler de üreticilerin ekonomik açıdan en az riski barındıran sözleşmeli çiftçilik gibi çözümlere yönelmesine yol açmaktadır. Bunda devletin alıcı konumdan çekilmesi ve yerini piyasa dinamiklerine bırakarak, üreticilerin teknik destek, finansman, pazara erişim vb konularda alternatif modellerden yoksun bırakılmasının etkisi açıktır (Keyder ve Yenal, 20।4). Önemli bir
OÖK kıtası olan Avrupa'da, kentleri birbirine bağlayan ağlar üzerinde yapılan çalışmalarda OÖK merkezleri arasında karşılıklı bağımlılı̆ın ve tamamlayıcılığın giderek artması (Yazar, 2006), Türkiye gibi gelişen ülkelerin OÖK politikaları bakımından dayanışma ve ağ ilişkilerini öne çıkarmaktadır. Castells'in de altını çizdiği, yarışmacılığa dayanarak gelişen kademelenme yerine bağlantıya ve işbirliğine dayalı bir ağ sistemi üzerinden hareket edildiğinde özellikle OÖK'ler, kentleşme sorunları karşısında daha dirençli olabilecekler (Yazar, 2006) ve kırın ekonomik açıdan alternatif yaklaşımlarla buluşmasına imkan yaratabileceklerdir.

İçinde bulunduğumuz dönemde, kentleşmeye dayalı geniş kapsamlı çalışmaların, varılan teknolojik altyapı ve erişim kolaylıkları ile birlikte düşünüldüğünde özellikle de ekonomik gelişme bakımından ağ ilişkilerini kuvvetlendirdiği bilinmektedir. Bu ilişkilerin içeriği sadece ekonomik olmayabileceği gibi kır-kent ilişkilerinin içinde bulunduğu bölgeler bakımından da farklılıklar gösterebilecektir. İletişim ve üretim ağlarının gelişmesi üzerine sınır ve kademelenme kavramlarının günümüzde önemini yitirmeye başladığı kentler, bir ilişkiler ağının parçası olarak ele alınabilmekte ve Tekeli'nin (2006) de işaret ettiği gibi bu ağ ilişkileri tek yönlü bir ilişkiden, karşılıklı etkileşime yönelen bir sürecin "dayanışma mekanizması” olarak değerlendirilebilmektedir. Farklı fonksiyonlar taşıyan kentlerin, düğüm noktaları olarak yakın ve uzak çevresi ile kurduğu yersel olmayan ilişki ağları, kentlerin içinde bulunarak etkileşime girdiği bölge boyutunu da içerebilirken (Erkan, 2007); kırsal alanların 'içsel' yapısı ile 'dışsal' faktörlerin ilişkisini kurma gereği ve ağ ilişkisinin kırsal alanları anlamada doğru bir yaklaşım olduğuna dair çalışmalar da önem kazanmaktadır (Murdoch, J.,2000). Bu çalışmalardan birinde Gülümser (2010), ürünözellikle bilgi-transferini sağlayan ağların, kırsal bölgelerin ulaşım ve erişim imkanlarıyla olan ilişkisine değinerek bu ilişkinin gücünün, kırsal kesimde yerel-sıcak noktalar oluşumunda etkili olabileceğini ortaya koymaktadır. Belirli yapısal sorunlarına rağmen Türkiye'nin 2000'li yıllarda ulaşım, haberleşme ve bilişim hizmetleri altyapısında gerçekleştirdiği iyileşmelerin, kırsal ve kentsel alanlar arasındaki erişimleri güçlendirdiği ve fonksiyonel ilişkilerin çeşitlenerek köyler ve şehirlerarasındaki geleneksel bağımlılık ilişkilerinin yerini ortaklık ve işbirliği ilişkilerine bıraktığı yeni bir sürecin oluşmaya başlaması (Ulusal Kırsal Kalkınma Stratejisi, 20I4) çalışmanın çözüm yaklaşımındaki kentleşme-dayanışma-ağ ilişkisine temel oluşturmaktadır. Artık şehirlerin ağ ilişkisine dayalı, çok merkezli ve dengeli bir yerleşim sistemi oluşturması gündemi, Türkiye'nin üst ölçek bölgesel ve kentleşme politikalarında da yerini almıştır (Kalkınma Bakanlığı, Türkiye Bölgesel Gelişme Ulusal Stratejisi-20।4-2023, 2015).

Bu çalışmada, önerilen çözüm yaklaşımında, OÖK’lerin hem güçlü bir kır-kent ilişkisini (kırsal hinterlandı) hem de dayanışmacı bir ağ ilişkisini temsil edebilmesi hedeflendiğinden, buna 
dönük bir yerleşim yapısına ulaşabilmek için söz konusu niteliklerin Türkiye özelinde kapsamlı-güncel bir şekilde ve doğru yerleşme ölçeğinde temsil edilebilmesi amaçlanmaktadır. Dayanışma ve ağ ilişkileri, birbirini destekleyen iki faktör olarak ele alınırken ağırııla tarıma dayalı yerel ekonomiler bağlamında orta ölçekli kentlerin serbest piyasa koşullarının etkisinden uzaklaşabilmesi ve alternatif bir pazar imkanı yaratabilmesi için son derece önemlidir. Ancak her iki kavramın mekanda ve iller düzeyinde nasıl bir organizasyonel yapı içinde uygulamaya konu olacağı, çalışmanın kapsamı dışında tutulmuştur. Her iki kavram, daha önce de belirtildiği gibi önerilen çözüm yaklaşımında, OÖK'lerin temel niteliğinin yerel ekonomileri geliştirici birer unsuru olarak kabul edilmiştir. Çalışmanın çözüm yaklaşımı için gerekli OÖK tanımına ulaşabilmek adına -bir sonraki bölümde detayları aktarılacağı üzere- 3 adımdan oluşan bir yöntem kullanılmıştır. İlk olarak literatürdeki örnekler, ulusal ve uluslararası kabuller dikkate alınırken, yerleşim ölçeğini belirlemek için illerin sahip olduğu toplam nüfus bakımından genel bir aralık belirlenmiştir. Daha sonra, bu aralığa girebilen iller üzerinden kırkent nüfus dengesi ve sektörel açıdan kırsal ekonomileri içerme bağlamında ikinci bir daraltmaya gidilerek, kır-kent ilişkileri ve kırsallığın temsiliyeti sağlanmaya çalışılmıştır. Aynı zamanda kırkent dayanışması için de önemli olan bu adımdan sonra, kır-kent ilişkilerinin ekolojik yansıması, dayanışma ve ağ ilişkilerinin temsiliyeti bakımından belirli değişkenleri içeren nihai bir karşılaştırma tablosu elde edilerek, il düzeyinde OÖK’ler belirlenmiştir.

Çalışmada kır-kent ilişkisi ve kırsallığın OÖK üzerinden temsiliyeti sadece kırsal nüfus oranı ve tarımsal işgücü üzerinden değil, aynı zamanda rekabet yerine dayanışmaya bağlı, yerelde ve yatay ilişkiler/ağlar üzerinden gelişebilecek ekonomiler bakımından da önemlidir. Sonuçta, ilişkilerden daha fazla yararlanabilecek bir örgütlenme yapısının geliştirilmesi gerekmekte (Tekeli, 2006) ve bu amaçla çalışmada kentleşme içinde dayanışmacı bir ağsal ilişki öne çıkarılmaya çalışılmakta, ağlar, rekabetten paylaşıma/dayanışmaya geçişin aracı olarak işlevselleşmektedir. Bunun için öncelikle yerel örgütlülük, ticari ilişki ve pazara erişim kapasitesi, alternatif/aracısız (gıda vb.) ticari ağlar, teknoloji ve iletişim altyapısı gibi faktörler öne çıkmaktadır. Ancak bu bakımdan ülkemizdeki veri kaynakları ve yaygınlığının son derece sınırlı olduğu görüldüğünden; ikincil verilere dayalı çalışmanın bu aşamasında tüm iller bazında erişilebilir olan değişkenlerden yararlanılmıştır. Ayrıca ekolojik açıdan iyi durumda olabilme, tarımsal üretim bakımından gelişmiş (veya gelişme potansiyeli taşıyan) bir ekonomi ve kır üzerindeki kentleşme baskısının düzeyi de OÖK'lerin niteliklerini belirlemede dikkate alınan diğer faktörlerdir.

\section{Türkiye'de Orta Ölçekli Kentlerin Belirlenmesine İlişkin Bir Yöntem Denemesi}

Genel anlamda yerleşmelerin sınıflandırılmasında, belirli bir nüfus büyüklüğüne dair kırılmaların diğer nüfus değerlerin- den daha fazla dikkat çekmesi varsayımına göre kabuller yapılmaktadır (Jones'ten aktaran Çabuk ve Demir, 2010). Bu açıdan OÖK'ler, birbiriyle farklılaşan yöntem ve yaklaşımlar içinde ele alınırken, nüfus aralıklarına dayalı kabuller yaygınlık kazanmıştır. Nüfus yapısı dışında, 2000’li yıllarda önem kazanan OÖK'leri belirlemeye dönük çalışmaların farklı değişkenleri de içermeye başladığı görülmektedir. Bu değişkenlerden bazıları, en az I üniversitenin bulunması, baskın bir metropolün etki alanında olmama durumu, nüfus yoğunluğu, kentsel yerleşik alan büyüklügüü-oranı, aktif işgücü oranı, gelir dağılımı, lise ve ileri düzey eğitim durumu, trafik yoğunluğu-kirlilik, istihdam-işgücü, sosyo-ekonomik gelişmişlik vb. olarak sıralanabilir (www.smartcities.eu, E.T. 17.12.20I7; ESPON, 20I3, Živanović vd., 2014). OÖK'ler, tipolojik-işlevsel bir sınıflandırmaya ya da çok değişkenli bir tablo üzerinden sıralamaya da konu olabilmektedir. Örneğin Hildreth (2007), ekonomik rol ve etkilerine göre İngiltere OÖK'lerini sanayi, geçiş, kültürel miras/turizm, bölgesel hizmet, büyük kentsel bölge içi, üniversite/bilgi kentleri olarak 6'lı tipoloji üzerinden incelemiştir. Klaus (20I3) ise stratejik planlama kapsamında kuzey Avrupa OÖK'lerini bölgesel konumları dışında fonksiyonel rollerine göre mal-hizmet sağlayıcı ve dengeleyici, öncü gelişen, rahatlatıcı (relief) ve sınır-değişim-geçiş (gateway) kentleri olarak gruplamıştır. Amerika'daki OÖK'lerse Avrupa'daki eğilimden farklı olarak unutulan orta, metropol bölgelerin küçük merkezleri, daralan-ayrışan (yaş, gelir, sınıf odaklı) kentler olarak farkındalık odaklı tanımlanmıştır (Fulton, 2002). Ülkemizdeyse görece ulusal ölçekteki en güncel yerleşim sınıflandırmasına yer verilen Türkiye Bölgesel Gelişme Ulusal Stratejisi'nde (Kalkınma Bakanlığı, 20I5) yerleşmeler Metropoller, Büyüme Odakları, Bölgesel Çekim Merkezleri, Yapısal Dönüşüm İlleri, Öncelikli Gelişme İlleri ve Kırsal Alanlar şeklinde belirlenmiş, yerleşim ölçeklerineyse değinilmemiştir. Ülkemizdeki çalışmalarda yaygın olarak OÖK'ler, kentsel ya da toplam nüfus büyüklüğü aralıklarına göre belirlenirken, Yazar'ın (2006), OÖK'leri belirli bir nüfus aralığı dışında, sosyo-ekonomik gelişmişlik düzeylerine göre grupladığı çalışması yöntem bakımından farklılaşan tek çalışmadır. Türkiye'de bir yerleşimin nüfusu 20.000-750.000 aralığındaysa kent; 750.000 ve üzerindeyse de büyükşehir olabilmekte (442 ve 5216 Sayılı Kanunlar) ancak bu çok geniş nüfus aralığında küçük ve orta büyüklükteki kent yerleşimleri için bir tanımlama yapılmamaktadır. Dolayısıyla bu ikili yapının (kent-büyükşehir) yetersizliği, kentlerin sınıflandırılmasında bilimsel ölçütlere dayalı yeni düzenlemelerin gerekliliğini ortaya çıkarmaktadır (Çabuk ve Demir, 20 I0). Sonuçta, ülkemizdeki OÖK çalışmalarının özellikle de kentleşmeye dayalı sorunların çözümü bakımından farklı boyutları içerme ve nüfus dışı değişkenler üzerinden daha gelişkin bir temsil gücüne ulaşabilme bakımından yeterli düzeyde olmadığı görülmektedir.

Bu çalışma, OÖK’ler üzerinden kentleşmeye dayalı çözümleyici, yapıcı bir süreç yaratılabilmesi için gerekli tanımlamaya 3 temel adımdan oluşan bir yöntemle ulaşmaktadır. Çalışma, 
yerli ve yabancı örneklerde kullanılan OÖK belirleme yöntemlerinden, kullandığı değişkenlerin kapsamı ve türü yanında, öne çıkardığı OÖK nitelikleri bakımından da farklılaşmaktadır. II düzeyindeki ikincil verilerin kullanıldığı yöntemde, sırasıyla nüfus aralığı ve kır-kent nüfus oranlarına bağlı tespitler ve tarımsal işgücü yapısı ilk 2 adımda belirleyici olmuştur. Son adımdaysa iller, kentsel ve kırsal nüfus oranları yanında sektörel işgücü yapıları, gelişmişlik düzeyleri, çevre performansları, ulusal pazara erişim düzeyleri, internet kullanıcı sayıları ve tarımsal üretime dayalı kooperatif sayıları bakımından çok değişkenli bir tablo oluşturularak irdelenmiştir.

Yöntem aşamalarında kentsel denge arayışı ve kır-kent ilişkilerine dayalı dayanışmayı temsil edebilmek adına öncelikle belirli bir nüfus aralığı ve kır-kent nüfus oranı dikkate alınmıştır. Ülkemizde son dönemde uygulanan büyükşehir yasaları ile birlikte kır-kent nüfus ayrımında yeni bir sürece girilmiş ve gerek $A B$ 'ye uyum gerekse son yasal düzenlemelere elverişli bir tanımlama çalışmasına TÜiKK öncülüğünde başlanmış ancak bu çalışma henüz tamamlanamamıştır (http://www.resmiistatistik.gov.tr, E.T. 25.09.2017). Bu açıdan AB ve OECD tarafından belirlenen ve benzer çalışmalarda sıkça kullanılan kırsal-kentsel tipoloji kabulleri dikkate alınmıştır (Tablo 2).

Burada, kırsal nüfusun oranı dışında, kırsal üretim yapılarını ve ağ ilişkilerine bağlı dayanışma ekonomilerini ortaya koya-

Tablo 2. Nüfus oranları bakımından EUROSTAT ve OECD'ye göre kent-kır tipolojileri

\begin{tabular}{|c|c|c|}
\hline & EUROSTAT* & OECD** \\
\hline $\begin{array}{l}\text { Kentsel ağırlık yerleşim } \\
\text { (Kentsel nüfus oranı) }\end{array}$ & $\% 80 \geq$ & $\% 75 \geq$ \\
\hline $\begin{array}{l}\text { Kent-Kır arası yerleşim } \\
\text { (Kırsal nüfus oranı) }\end{array}$ & $\% 20-50$ & $\% 15-50$ \\
\hline $\begin{array}{l}\text { Kırsal ağırlıklı yerleşim } \\
\text { (Kırsal nüfus oranı) }\end{array}$ & $\% 50 \geq$ & $\% 50 \geq$ \\
\hline
\end{tabular}

*EUROSTAT: AB İstatistik Ofisi: http://ec.europa.eu/eurostat/statistics-explained/index.php/Urban-rural_typology; **OECD: Ekonomik Kalkınma ve İşbirliği Örgütü: OECD, 2011. bilmek için küçük üreticiler, yerel pazarlar ve ticaret ağları ile ekonomik örgütlenme biçimleri vb. konularda yeterli veri bulunamamıştır. Bu nedenle kır-kent ilişkilerinde kırsal ekonomileri içeren temel örgütlenme ve dayanışma biçimlerinin başında gelen 'tarımsal üretime dayalı kooperatiflere' ilişkin ilgili bakanlık verilerinden yararlanılmıştır. Yöntem kapsamında, OÖK'lerin ağ ilişkilerine dair potansiyellerini ortaya koyabilmek için -farklı ulaşım türlerine erişim düzeylerini de içeren- ulusal pazara erişim imkanları dikkate alınmış ve Türkiye Bölgesel Gelişme Ulusal Stratejisi'nin bu konuda il düzeyindeki analizlerinden yararlanılmıştır. Söz konusu analizler, ağ ilişkileri ve mekânsal boyutları bakımından bu çalışma ile koşut bir yaklaşımı içermesi nedeniyle tercih edilmiştir. Ulusal pazara erişim, arka planında bölgeler arası denge ve kentsel gelişim bakımından ulusal pazar bütünleşmesine yatkınlığı ortaya koyarken; bölgelerin temel fonksiyon alanlarına erişim imkanlarını da temsil etmesi nedeniyle çok yönlü ve özellikle de ağ ilişkileri bakımından önemli bir göstergedir (Şimşek, 20I5). Buna ek olarak yakın dönemde öne çıkan çevrimiçi (online) ticaretin kır-kent arasındaki tarımsal üretime dayalı ekonomilerde yarattığı cazibe ve uzak mesafeli ekonomi fırsatları bakımından internet erişiminin (sabit ve mobil) niceliği de bir diğer değişken olarak dikkate alınmıştır. Diğer yandan çözüm yaklaşımının temel hedeflerinden biri olan kentsel denge arayışında, yakın çevrelerini de etkileyebilecek bir gelişme dinamiği yaratabilmeleri için OÖK’lerin belirli bir gelişmişlik düzeyine sahip olmaları gerekmektedir. $\mathrm{Bu}$ açıdan Birleşmiş Milletler Kalkınma Programı (UNDP) tarafından ülkelerin gelişmişlik seviyelerini ölçmek üzere eğitim-sağlık-gelir endekslerinin bütünleşmesi ile elde edilen İnsani Gelişme Endeksi (IGE), gelişmeyi il düzeyinde ifade edebilmek için kullanılmıştır. Bu amaçla Özpınar ve Koyuncu'nun Türkiye'deki illeri farklı düzeylerde grupladıkları (Tablo 3) IGE analiz raporundan yararlanılmıştır. Gelişme düzeyi bakımından ayrıca farklı sektörlere bağlı işgücü dağılımları da il düzeyinde dikkate alınmıştır.

Son olarak, kır-kent ilişkiselliğinde ve kırsal yapıların öne çıkarılmasında belirli bir ekolojik hassasiyeti ortaya koyabilmek, doğal çevredeki kayıpların oranını/niteliğini ve bunların çevresel yaşam kalitesine etkisini temsil edebilme amacıyla yöntemin son aşamasında, TÜiK tarafından 2016 yılında yayınlanan

Tablo 3. IGE bakımından farklı düzeylerde yer alan il sayıları (Özpınar ve Koyuncu, 2016)

\begin{tabular}{lccc}
\hline Düzey kodu & Endeks aralığı & Insani gelişmişlik endeks düzeyi & iı Sayısı \\
\hline I & $0-0.336$ & Çok düşük insani gelişme grubu & 13 \\
2 & $0.337-0.523$ & Düşük insani gelişme grubu & 24 \\
3 & $0.524-0.667$ & Orta insani gelişme grubu & 33 \\
4 & $0.668-0.789$ & Yüksek insani gelişme grubu & 11 \\
5 & $0.790-0.943$ & Çok yüksek insani gelişme grubu & 0 \\
\hline
\end{tabular}


“illerde Yaşam Endeksi-2015” başlıklı araştırma raporunun il düzeyindeki çevre performanslarını içeren sonuçlarından yararlanılmıştır. Birer indeks değeri olan bu sonuçlarda, hava kirliliği, orman varlığı, atık hizmeti verilme oranı, gürültü kirliliği ve yerel yönetimlerin sağladığı çevre temizliği hizmeti konularındaki il bazlı verilerden yararlanılmıştır.

\section{Yöntemin Adımları}

\section{Genel Nüfus Aralığının Belirlenmesi}

Yöntem aşamasında karşılaştırmalara imkan verebilmesi ve kolay gruplama yapılabilmesi için OÖK'ler dışındaki iller geçici olarak 3 gruba ayrılmıştır: Ana metropoller, Büyükkentler ve diğer kentler. Nüfus aralığı belirlenirken il ya da kent nüfusunun kabulünün farklı sonuçlar doğurabileceği ortadadır ancak OÖK'lerin kır-kent ilişkisine dayalı temsiliyetini de güçlendirmesi (kırsal hinterlandı içermesi) bakımından il nüfuslarına dayalı bir aralık belirlenmiştir. Bu amaçla,

I. Hem metropol/büyükşehir hem de az gelişmiş kent niteliğinin dışında olma ve nüfus gelişimi bakımından bu yapılara yaklaşma eğilimlerinden uzak olma.

2. Türkiye'deki idari yerleşme sistemi içinde belirlenen nüfus kabulleri bakımından büyükkent/büyükşehir olmayan bir kent için en alt (20.000) ve en üst (750.000) nüfus eşiklerine göre ara yerleşim büyüklüğü belirleyebilme.

kriterleri dikkate alınmıştır. Türkiye'nin nüfus yapısına bakıldığında, neredeyse ortalama I milyonluk nüfusa sahip il düzeyine ulaştığı ve ağırlıklı nüfusun büyükşehirler için belirlenmiş alt eşik olan 750.000 ve üzerindeki yerleşmelerde toplandığı görülmektedir. Büyükşehirler dışarıda bırakıldığındaysa ortalama il nüfusu neredeyse I/3 oranında azalmaktadır (Tablo 4).
Ayrıca ülke nüfusunun 2023 yılında 5.3 milyon artarak 84.3 milyon olacağı öngörülmektedir (TÜiK, 20I7a).

Tüm büyükşehirlerin dışarıda bırakıldığı durumda, 5 I il ülke nüfusunun \%22.5'ini temsil etmekte ve bu kümenin nüfus aralığı 82.193 ile 7l4.523 arasında değişmektedir (Tablo 5). Çalışmada OÖK arayışı bu 5 I il kümesinin bir alt kümesi olacağından; belirlenecek il nüfus aralığının kapsayıcılığı son derece önemlidir. Buna göre OÖK tanımı için 3 büyük metropolün dışarıda bırakıldığı durumdaki ortalama il nüfusu değerini (684.453) geçmeyen ve tüm büyükşehirlerin dışarıda bırakıldığı durumdaki ortalama il nüfusunun (352.495) da altına düşmeyen bir aralığa sahip olması uygun bulunmuştur (Tablo 5).

Alt sınır için ülkemizdeki geçmiş çalışmalarda yaygın olarak il nüfus değeri 100.000 kabul edilmiştir. Ancak güncel nüfus değerleri ve yakın gelecekteki artış eğilimleri dikkate alındığında, bu değerin düşük olduğu görülmektedir. 1980'li ve 90'lı yıllarda OÖK sınıflamalarında genel anlamda alt eşik olarak nüfus değeri 100.000 olarak kabul edilse de o dönemden bu yana ülke nüfusunun 50 milyondan 80 milyona ulaşmış olması ve büyük oranda kentsel nüfus artışı göstermesi oldukça önemlidir. Günümüzde 100.000 kişiden az nüfusa sahip sadece 2 il (Tunceli ve Bayburt) bulunmaktadır. Bu bağlamda çalışmada OÖK’ler için günümüz nüfus yapısı dikkate alınarak 200.000-600.000 aralığına giren iller ilk adım için uygun bulunmuşlardır (Şekil 2).

Diğer yandan ilerleyen yıllarda il bazlı nüfus değişimleri de dikkate alındığında, TÜiK'in 20 I3-2023 dönemini içeren nüfus projeksiyonu, bu aralığın alt ve üst sınırındaki kaymaları gözler

Tablo 4. Türkiye'de farklı il gruplarına göre nüfus yapıları (TÜiK, 20I7)

\begin{tabular}{|c|c|c|c|c|c|c|c|}
\hline & 81 ì & $\begin{array}{l}\text { İstanbul- } \\
\text { Ankara- } \\
\text { İzmir }\end{array}$ & $\begin{array}{c}\text { İstanbul- } \\
\text { Ankara- } \\
\text { İzmir Hariç } \\
\text { Türkiye } \\
\text { (78 il) }\end{array}$ & 30 Büyükşehir & $\begin{array}{l}30 \text { Büyükşehir } \\
\text { Hariç Türkiye } \\
\text { (5I il) }\end{array}$ & $\begin{array}{l}27 \text { Büyükşehir } \\
\text { (İstanbul- } \\
\text { Ankara-İzmir } \\
\text { dışındaki) }\end{array}$ & $\begin{array}{l}27 \text { Büyükşehir } \\
\text { Hariç (İstanbul- } \\
\text { Ankara-İzmir } \\
\text { dışındaki) } \\
\text { Türkiye (54 il) }\end{array}$ \\
\hline Toplam nüfus (mil.) & 79.8 & 24.4 & 55.4 & 61.8 & 18 & 37.4 & 42.4 \\
\hline $\begin{array}{l}\text { Ülke nüfusundaki } \\
\text { payı (\%) }\end{array}$ & 100 & 30.1 & 69.4 & 77.4 & 22.5 & 46.8 & 53.1 \\
\hline Ortalama il nüfusu & 985.369 & 8.124726 & 684.453 & 2.061255 & 352.495 & 1.387536 & 784.285 \\
\hline
\end{tabular}

Tablo 5. Türkiye'de farklı il gruplarına göre nüfus yapıları (TÜiK, 20।7)

\begin{tabular}{lcccc}
\hline & Ülke nüfusundaki payı (\%) & il nüfus aralı̆̆ı & Ortalama il nüfusu & Medyan il nüfusu \\
\hline Istanbul-Ankara-Izmir hariç iller & 69.4 & 2.9 milyon - 82.193 & 684.453 & 501.791 \\
30 Büyükşehir hariç iller & 22.5 & $714.523-82.193$ & 352.495 & 331.048 \\
\hline
\end{tabular}




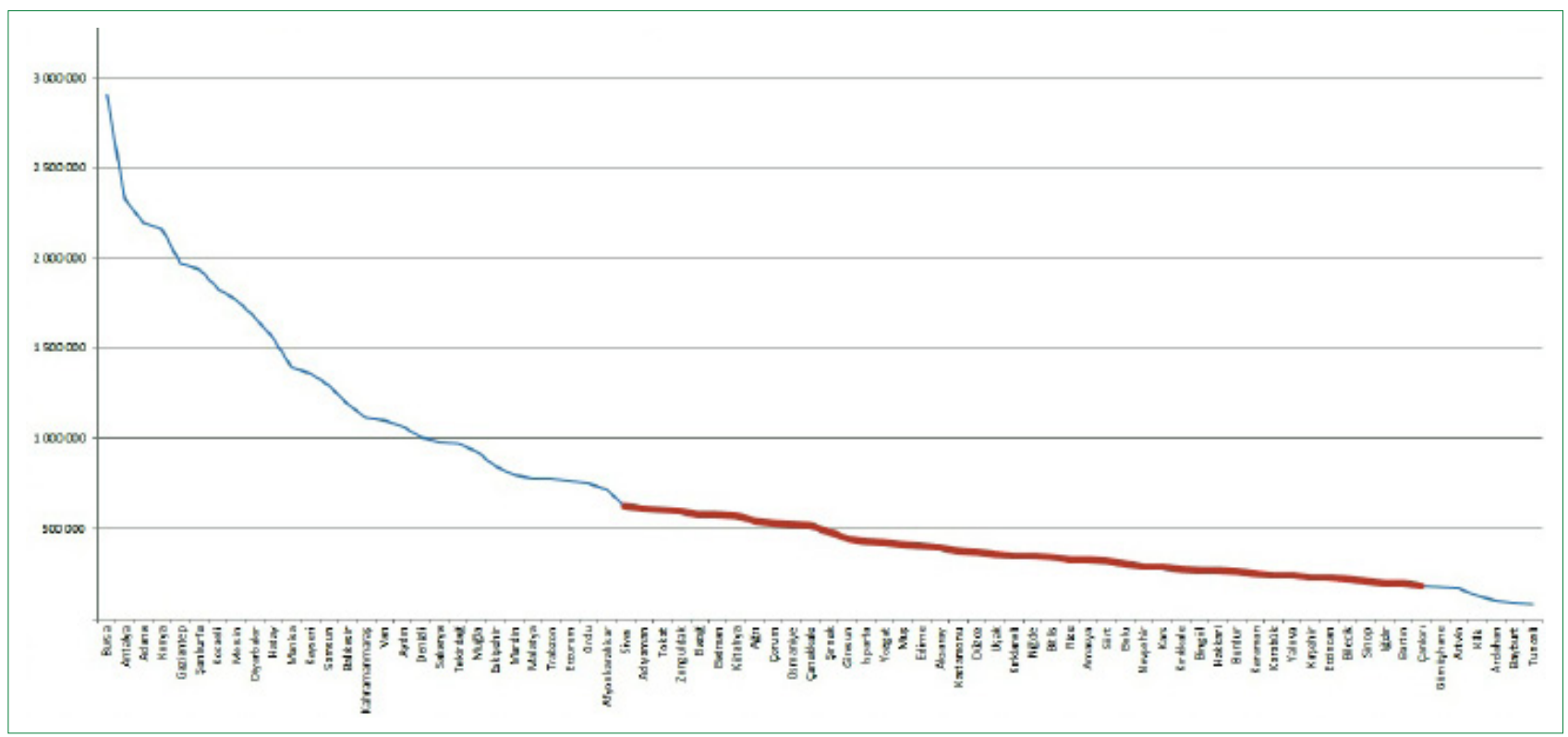

Şekil 2. İlk adım için uygun bulunan OÖK nüfus aralığının ülke nüfus dağılımdaki yeri (İstanbul, Ankara ve İzmir grafiğe dahil edilmemiştir).

önüne sermektedir (Tablo 6). Batman 2023'de belirlenen nüfus aralığının üst sınırını geçerken Sinop ise alt sınırın altında kalmaktadır. Tablo 6'daki diğer illerse bugün için aralığın dışında kalırken, 2023'te aralığın içinde yer alabileceklerdir. Tüm bu illerin 20।3-2023 nüfus gelişimlerine bakıldığında, aralığın üst sınırı dışına çıkan Batman ile nüfus kaybı yaşayarak aralığa dahil olabilecek Adıyaman, Sivas ve Tokat OÖK grubuna dahil edilmişlerdir. Iğdır nüfus artışı ile bu gruba dahil olurken, Sinop ise nüfus kaybı eğilimi göstermesine rağmen OÖK'lerin nüfus tutma potansiyelleri dikkate alınarak aralığın içinde tutulmuştur.

Sonuç itibari ile ilk adım sonunda OÖK olarak belirlenen iller kümesi, büyükşehir olmayan 5 I ilden 43'ünü içermiştir (Tablo 7). Bu kümenin ortalama il nüfusu 380 bin ve toplam nüfusu 16.3 milyondur (5I il toplam nüfusunun \%90'ı).

Tablo 6. Belirlenen nüfus aralığının alt ve üst sınırındaki illerin TÜiK-2023 yılı nüfus projeksiyonuna göre öngörülen değişimleri (TUIK, 20I7a)

\begin{tabular}{l|c|c}
\hline & $\mathbf{2 0 1 6}$ & $\mathbf{2 0 2 3}$ \\
\hline Batman & 576.899 & 667.742 \\
\hline Adıyaman & 610.484 & 599.291 \\
Sivas & 621.224 & 582.283 \\
Tokat & 602.662 & 561.419 \\
Çankırı & 183.880 & 206.231 \\
lğdır & 192.785 & 204.082 \\
Sinop & 205.478 & 191.604 \\
\hline
\end{tabular}

Aralı̆̆a uygun nüfus değerleri renklendirilmiştir.

\section{Nüfusun Kır-Kent Dengesinin Belirlenmesi}

Ülkemizde kır ve kent kavramlarının merkezi yönetim tarafından yeniden tanımlanması süreci henüz neticelenmemiş olduğundan, mevcut çalışmalarda ortak bir kabule ulaşmak mümkün değildir. Kırsal ile kentsel alanların birbirinden ayrıştırılması konusunda her ülke sosyo-ekonomik göstergelerine dayanarak kendi tanımlamasını yapmakta ve doğaldır ki bu nedenle tanımlar evrensel olarak tektipleşememektedir (Pizzoli ve Gong, 2007). Bununla birlikte yaygın olarak, OECD ve $A B$ tarafından geliştirilmiş olan mekânsal tipolojiler kentkır ayrımı ve tanımlarında kabul görmektedir (Gülümser vd., 20I0a). Bu iki uluslar üstü kurumsal yapının belirlediği tipoloji kabullerinde, kırsal ağırıklı yerleşim yapısı aynı şekilde tanımlanırken (\%50 ve üzeri kırsal nüfus oranı), kent-kır arası ve kentsel ağırlıklı yerleşimlerde AB'nin kırsallığı daha az tem-

Tablo 7. Nüfus aralığı bakımından OÖK kabulüne uyan iller

\begin{tabular}{|c|c|c|c|}
\hline Adıyaman & Çankırı & Karaman & Rize \\
\hline Ağrı & Çorum & Kars & Siirt \\
\hline Aksaray & Düzce & Kastamonu & Sinop \\
\hline Amasya & Edirne & Kırıkkale & Sivas \\
\hline Batman & Elazı̆̆ & Kırklareli & Şırnak \\
\hline Bilecik & Erzincan & Kırşehir & Tokat \\
\hline Bingöl & Giresun & Kütahya & Uşak \\
\hline Bitlis & Hakkari & Muş & Yalova \\
\hline Bolu & Iğdır & Nevşehir & Yozgat \\
\hline Burdur & Isparta & Niğde & Zonguldak \\
\hline Çanakkale & Karabük & Osmaniye & \\
\hline
\end{tabular}


Tablo 8 . 30 büyükşehir dışında ülke ortalaması üzerinde tarım işgücü oranına sahip olan iller

\begin{tabular}{lccc}
\hline & Nüfus & Tarım işgücü (\%) & Kır nüfusu (\%) \\
\hline Ardahan & 98.335 & 66.2 & 61 \\
Artvin & 168.068 & 40.1 & 41 \\
Gümüşhane & 172.034 & 38.2 & 29 \\
Bartın & 192.389 & 36.3 & 58 \\
Bayburt & 90.154 & 50 & 38 \\
Kilis & 130.825 & 42.9 & 25 \\
TR Ort. & - & 33.4 & - \\
\hline
\end{tabular}

sil ettiği bilinmektedir. Çalışmanın kır-kent ilişkisini güçlü bir şekilde temsil edebilmesi için kırsal nüfus oranını daha fazla içeren OECD'nin \%।5-75 aralı̆ında kırsal nüfus barındırma kriterine uyan iller ikinci adıma uyan illeri temsil etmektedir. Bu noktada, OECD'nin bu tipoloji yaklaşımının bir ön safhası olan ve kırsal alanları kilometre kareye düşen 150 kişinin altında bir yoğunluk ile tanımlayan yaklaşımları da dikkate alınmıştır. Diğer yandan, kırsal nüfus oranı düşük olup, tarım işgücü oranı ülke ortalaması üzerinde olan illerin de dikkate alınması amaçlanmıştır. Bu bakımdan büyükşehirler dışında güçlü tarımsal işgücü değeri gösterse de, söz konusu iller gerekli il nüfus düzeyine sahip olamadıklarından 2. adımda gerekli koşulları sağlayamamaktadırlar (Tablo 8). Ayrıca OECD'nin nüfus yoğunluğu koşuluna uymayan Yalova ili (302 kişi/km2), çok güçlü tarımsal üretim yapısı ve toplam nüfusu itibariyle tabloda kalmıştır. Sonuçta bu kritere göre yapılan ikinci tabloda, ilk tabloda yer alan Kırıkkale ili, \% 12 kırsal nüfus barındırdığı için dışarıda kalmış ve diğer 42 il tabloda yer almıştır (Tablo 9).

\section{3. Çok Kriterli Niteliksel Yapının Belirlenmesi}

Yöntemdeki 3. adım, kır-kent ilişkisini, yerelde ekonomik gelişmeyi ve buna bağlı dayanışmacı ağ ilişkilerini temsil bakımından belirleyici olması beklenen birden çok kriter içermektedir. Bu adımda nüfus dışında işgücüne katııım oranı, çevre performans değeri, tarım-sanayi-hizmet sektörlerine ait işgücü oranları, ulusal pazara erişilebilirlik endeksi, IGE değerleri, mobil internet kullanımı ve son olarak da tarımsal üretime dayalı kooperatif verilerine dayalı olarak OÖK'ler bir tablo içinde belirlenmiştir. Kullanılan ulusal pazara erişim endeksi; herhangi bir ulaştırma modunu kullanan bireyin, bulunduğu merkezden gidebileceği tüm varış noktalarında elde edebileceği aktivite potansiyelini ifade etmekte (Şimşek, 2015) ve bir ilden diğer illere erişebilme kabiliyetini ortaya koyduğundan, dayanışmacı-ağ ilişkileri üzerinden yerel ekonomilerin gelişmesine dair taşıdığı potansiyel nedeniyle tabloda yer almaktadır. Özellikle kırsalda ve kır-kent ilişkilerinde yerel ekonomileri güçlendirme potansiyeli açık olan çevirimiçi (online) ticaret ile kırın doğal değerlerinden beslenen alternatif ekonomiler için internet altyapısı ve kullanım
Tablo 9. İkinci kademedeki 42 il

\begin{tabular}{|c|c|c|c|}
\hline iller & Kır Nüfusu (\%) & iller & Kır Nüfusu (\%) \\
\hline Adıyaman & 34 & Karabük & 24 \\
\hline Ağrı & 44 & Karaman & 27 \\
\hline Aksaray & 34 & Kars & 54 \\
\hline Amasya & 29 & Kastamonu & 37 \\
\hline Batman & 21 & Kırklareli & 29 \\
\hline Bilecik & 20 & Kırşehir & 22 \\
\hline Bingöl & 38 & Kütahya & 30 \\
\hline Bitlis & 42 & Muş & 59 \\
\hline Bolu & 29 & Nevşehir & 38 \\
\hline Burdur & 33 & Niğde & 44 \\
\hline Çanakkale & 41 & Osmaniye & 24 \\
\hline Çankırı & 30 & Rize & 33 \\
\hline Çorum & 26 & Siirt & 36 \\
\hline Düzce & 36 & Sinop & 42 \\
\hline Edirne & 28 & Sivas & 26 \\
\hline Elazı̆̆ & 23 & Şırnak & 38 \\
\hline Erzincan & 42 & Tokat & 36 \\
\hline Giresun & 34 & Uşak & 29 \\
\hline Hakkari & 45 & Yalova & 27 \\
\hline lğdır & 44 & Yozgat & 36 \\
\hline Isparta & 28 & Zonguldak & 38 \\
\hline
\end{tabular}

imkanları son derece önemlidir. Bilgi Teknolojileri ve İletişim Kurumu'nun ylllık istatistik bülteninde yer alan Genişbant Mobil İnternet Abone İndeksi (BTK, 2017) online iletişim potansiyelini en kapsamlı gösteren değişken olması ve ekonomik ağların yaratılabilmesi bakımından tabloda yer almaktadır. Sektörel iş gücü dağılımı ile içinde işsiz nüfusu da barındıran iş gücüne katılım oranı, bu konuda tamamlayıcı diğer göstergelerdir. Yerel ekonomilerdeki etkisi bir yana, özellikle kır ile kent ve kentlerin kendi aralarındaki tarımsal üretime dayalı dayanışmanın temsili bakımından Gümrük ve Ticaret Bakanlı̆ıı bünyesindeki tarımsal üretime dayalı kooperatif sayılarından oluşan veri seti de (GTB, 2018) bir diğer kritik değişken grubunu temsil etmektedir. Burada faal olmayan ancak düzenli toplantı ve işleyiş koşullarını yerine getiren kooperatifler de söz konusu değişken içine katılmış ve illerin bu konudaki potansiyelleri dikkate alınmaya çaIş̧ııışır. Bir diğer kooperatif bilgi kaynağı olan Gıda Tarım ve Hayvancılık Bakanlığı'na bağı̆ı -sadece 20 ile dair sınırlı bilgiler içeren- kooperatif verileriyse içerdiği eksik bilgiler ve güncellik sorunları nedeniyle kullanılamamışır. Kır-kent ilişkisi ve yaratacağı olumlu -başta ekolojik olmak üzere- etkiler bakımından illerin 'çevre performansı düzeyi' de son derece önemlidir. İl düzeyindeki hava kirliliği, orman varlığı, atık hizmeti, gürültü kirliliği ve yerel yönetimlerin çevre hizmetine ilişkin verilerden oluşan söz 
Tablo I0. Üçüncü adım sonucunda belirlenen OÖK kümesi ve diğer il gruplarına ilişkin özet bilgiler

\begin{tabular}{|c|c|c|c|c|c|c|c|c|c|c|c|}
\hline & \multicolumn{2}{|c|}{2018} & \multicolumn{5}{|c|}{2013} & \multirow{2}{*}{\begin{tabular}{|c|}
2015 \\
Çevre \\
Portormana \\
Ende kei
\end{tabular}} & \multirow{2}{*}{$\begin{array}{l}2015 \\
\text { Uluss/ Pasara } \\
\text { Gizilebifrik } \\
\text { Endeksi } \\
\text { (Yaylma) }\end{array}$} & \multirow{2}{*}{$\begin{array}{c}2018 \\
\text { Genizbont Internet } \\
\text { Aboens Indeksi } \\
\text { (1 000 kizi bugina } \\
\text { dagen mobil } \\
\text { abonelkier) }\end{array}$} & \multirow{2}{*}{\begin{tabular}{|c|}
2010 \\
1000 kigi bayıns \\
digen Tarmsal \\
Oretimle ligkif \\
Kooperatí Saysı
\end{tabular}} \\
\hline & $\begin{array}{l}\text { Kentsel } \\
\text { Neifus (69) }\end{array}$ & $\begin{array}{c}\text { Krosal } \\
\text { Neifus (M) }\end{array}$ & 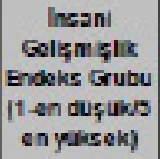 & $\begin{array}{l}\text { 5 goeune } \\
\text { Katilma } \\
\text { (19) }\end{array}$ & $\begin{array}{c}\text { Tanm } \\
1 ; \text { guea } \\
{[9 / 9]}\end{array}$ & $\begin{array}{c}\text { Sanayt } \\
\text { לgueu } \\
(35)\end{array}$ & $\begin{array}{c}\text { Hizenot } \\
4, g \mathrm{cu} \\
(99\end{array}$ & & & & \\
\hline Adipoman & 00 & 34 & 2 & 43,3 & 50,8 & 18,4 & 30,8 & 0,38 & 3.0 & 006 & 5,32 \\
\hline Aksaray & 06 & 34 & 2 & 49,8 & 42,2 & 22 & 35,8 & 0,40 & 3.0 & 754 & 1,12 \\
\hline Amasya & 71 & 20 & 3 & 48,0 & 40,3 & 14,0 & 39,8 & 0,70 & 23 & 708 & 20,80 \\
\hline Batman & 70 & 21 & 2 & 35.3 & 26.5 & 23.5 & 50 & 0,36 & 3.0 & 511 & 1.20 \\
\hline Gikeik & 80 & 20 & 3 & 40,8 & 21,3 & 37,1 & 41,7 & $0,7 e$ & 1.4 & 504 & 3,97 \\
\hline Bolu & 71 & 29 & 4 & 54,1 & 29.8 & 22,7 & 47,5 & 0,68 & 22 & 500 & 14,24 \\
\hline Burdur & 67 & 33 & 3 & 50,2 & 40,3 & 17,8 & 39,8 & 0.05 & 1.0 & $B 64$ & 9.88 \\
\hline Conabkale & 80 & 41 & 3 & 49,8 & 38,8 & 17,5 & 43,8 & 0,06 & 24 & 826 & 11,10 \\
\hline Cronkri & 70 & 30 & 2 & 40,2 & 45,1 & 10,3 & 39,5 & 0,02 & 1.2 & 802 & 2,04 \\
\hline Corum & 74 & 28 & 2 & 48.8 & 37.4 & 27 & 35.6 & 0,66 & 4.4 & 569 & 22,59 \\
\hline Dizoe & 04 & 30 & 2 & 56,3 & 32,1 & 33,3 & 34,0 & 0,44 & 32 & 604 & Q1,12 \\
\hline Eairne & 72 & 29 & 3 & 54.7 & 35.6 & 18 & 48.4 & 0,57 & 1,0 & 280 & 26,17 \\
\hline 日aอg & $7 T$ & 23 & 3 & 50,1 & 28,6 & 20,1 & 81,4 & 0,02 & $3 . \theta$ & 508 & 4,03 \\
\hline Erincan & 58 & 42 & 3 & 50,0 & 38,0 & 12,5 & 49,8 & 0.57 & 1,1 & $\cos$ & 3.57 \\
\hline Qiresun & 06 & 34 & 3 & $55, \theta$ & 48,1 & 17 & 37 & 0,80 & 28 & 553 & 82,74 \\
\hline lg̈dr & 50 & 44 & 1 & 50,4 & 49 & 12,3 & 39,7 & 0,20 & 0.0 & 810 & 0,32 \\
\hline bparta & 72 & 29 & 4 & 50.8 & 40.8 & 14.7 & 44.5 & 0,87 & 3.0 & 570 & 20,82 \\
\hline Korabik & 70 & 24 & 4 & 57,5 & 15 & 26,8 & 88,2 & 0,79 & 1.5 & 604 & 3.52 \\
\hline Karaman & 73 & 27 & 3 & 50.5 & 39.7 & 25.1 & 35.2 & 0,82 & 1,1 & 010 & 1,11 \\
\hline Kors & 46 & 54 & 2 & 56,0 & 48,3 & 18,4 & 30,3 & 0,37 & 1.3 & 526 & 0,43 \\
\hline Kastamonu & 63 & 37 & 2 & 50,0 & 52,8 & 12,7 & 34,5 & 0.81 & 24 & $\cos$ & 2.84 \\
\hline Kunklareli & 71 & 20 & 3 & $52, \theta$ & 25 & 31 & 44 & 0,74 & 1.4 & 585 & 34,06 \\
\hline Kurgahir & 78 & 22 & 3 & 43,4 & 38,0 & 10,8 & 41,5 & 0.81 & 1.0 & 806 & 10.22 \\
\hline Kitshys & 70 & 30 & 2 & 52,8 & 39 & 26,7 & 25,3 & 0,68 & 47 & 597 & 8.81 \\
\hline Nevpehir & 02 & 38 & 3 & 40,8 & 42,6 & 14,2 & 43,2 & 0,86 & 24 & 570 & 0,24 \\
\hline Nijo & 56 & 44 & 3 & 47,6 & 47,6 & 18,4 & 34,1 & 0,83 & 25 & 583 & 2,00 \\
\hline Osmanive & 70 & 24 & 2 & 40,3 & 26,8 & 20,0 & 44,6 & 0,98 & 3.7 & 502 & 7,23 \\
\hline Rize & 87 & 33 & 4 & 57.4 & 36.3 & 23.8 & 38.8 & 0,71 & 1,8 & 028 & 7,88 \\
\hline Sinse & 58 & 42 & 2 & $58, D$ & 36,2 & 25 & 39,8 & 0,60 & 0.7 & 671 & 3,85 \\
\hline Sivas & 74 & 28 & 2 & 50,5 & 37,8 & 21,8 & 40,3 & 0.83 & 40 & 587 & 4.28 \\
\hline Tokat & 84 & 36 & 2 & 47,4 & 49,1 & 18,3 & 24,8 & 0,64 & 47 & 545 & 13,21 \\
\hline$U_{f} a k$ & 71 & 28 & 3 & 59,8 & 39,5 & 20,4 & 34,1 & 0.71 & 24 & 802 & 272 \\
\hline Yalova & 73 & 27 & 4 & 52,4 & 11,7 & 29 & 50,2 & 0,74 & 1.5 & 1.062 & 0.22 \\
\hline Yosgat & 04 & 30 & 2 & 53,2 & 48,8 & 18,4 & 32,0 & 0,90 & 3.7 & 810 & 2.85 \\
\hline Zonguldat & 82 & 38 & 3 & 57.4 & 26.2 & 30.4 & 43.5 & 0,81 & 31 & 040 & 22,17 \\
\hline Türkiye & 82 & 3 & 25 & 50.1 & 39.4 & 22.4 & 442 & 0.59 & 6.85 & 601 & 1158 \\
\hline Ana Motropeller & 100 & 0 & 3.6 & 509 & 5.7 & 28.7 & 64.8 & 0.60 & 5390 & 726 & 420 \\
\hline Buyulegshirler & 100 & a & 2,7 & 420 & 288 & 20,4 & $44 \beta$ & 0,03 & 2,80 & 500 & 13,31 \\
\hline ockister & 68 & 32 & 2,7 & 81,5 & $3 \pi, 8$ & 21,0 & 41,0 & 0,80 & 2,80 & 606 & 13,94 \\
\hline Dföper iller & 80 & 40 & 1,7 & 43,9 & 372 & 18,4 & 48,4 & 0,40 & 1,80 & 5,84 & 5,14 \\
\hline
\end{tabular}

konusu karma ölçüt, aynı zamanda OÖK’ler için yaşam koşullarının sürdürülebilirliği ve üzerlerindeki kentleşme baskılarının etkileri bakımından da önemlidir. Son olarak eğitim-sağık-gelir endekslerinin bütünleşmesi ile elde edilen il bazlı IGE, orta ölçekli yerleşmelerin sadece ekonomik değil, daha geniş ölçekte gelişme düzeyi ve potansiyelini ortaya koyabilecek bir ölçüttür (Tablo 10).

2. adımda yer alan OÖK'ler, bu adımda çok sayıda ölçüt bakımından aynı tabloda yer alırken; IGE düzeyi en düşük (I) olan iller (Ağrı, Bingöl, Bitlis, Şırnak, Siirt, Muş ve Hakkâri), gerek kendi gelişimlerini yeterli oranda sağlayamadıkları gerekse çevre illere gelişim yönünde çarpan etkiler sunamayacağı için, bu adımda OÖK grubundan çıkarılmışlardır. Bu noktada IGE değeri I olan Iğdır, gerek yüksek iş gücüne katılım ve tarım iş gücü oranları, gerekse 2023 yılı nüfus projeksiyonunda artış eğilimi gözlenen iller arasında olması nedeniyle OÖK kümesinde kalmıştır. Sonuç olarak, ilk adımda 42 olan OÖK sayısı, 3. adım ile birlikte 35'e inmiştir (Tablo 10).

Belirlenen OÖK'lerin coğrafi dağılımında orta ve orta-kuzey Anadolu illerinin sayıca fazla olduğu görülmektedir (Harita 


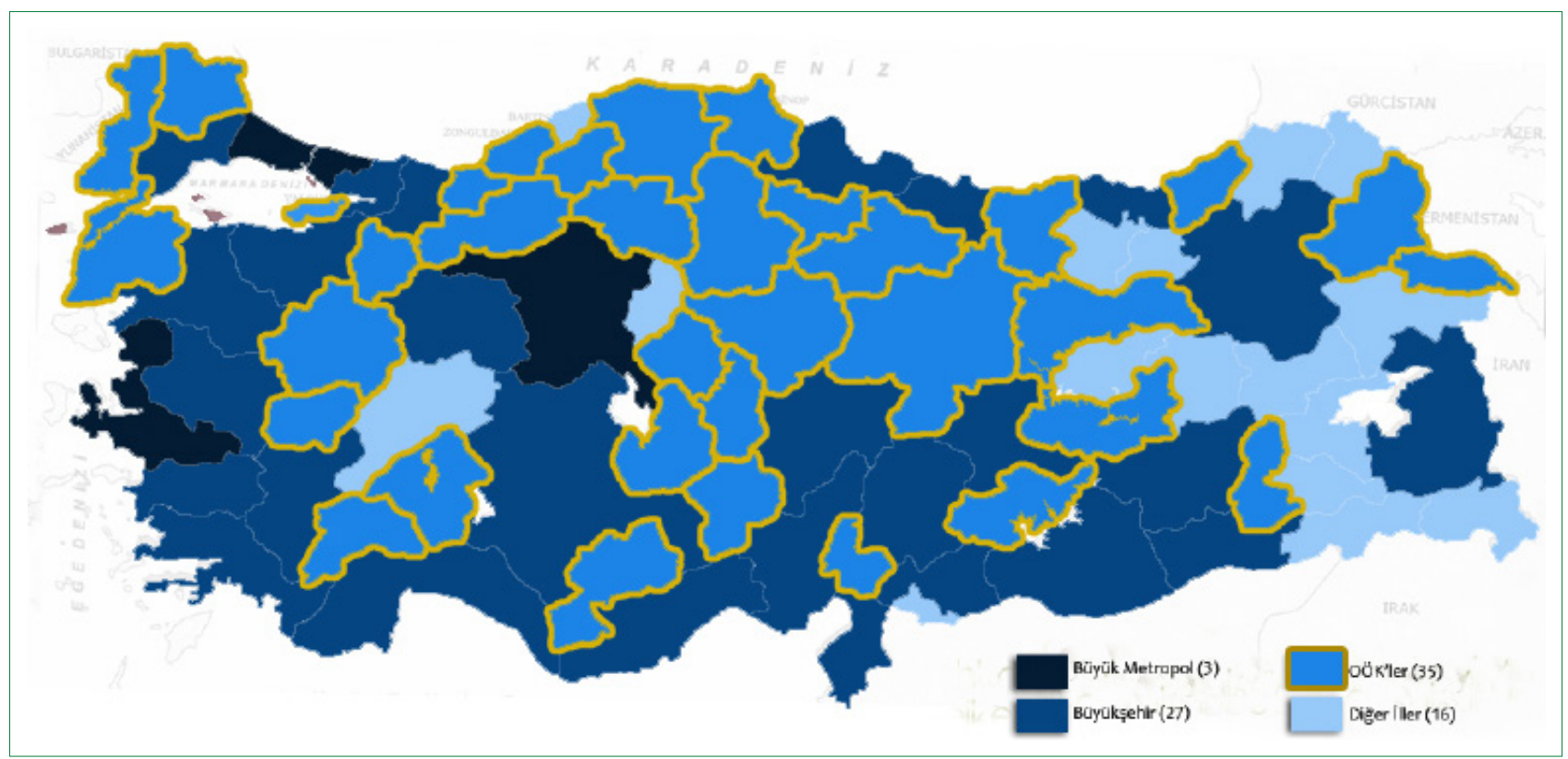

Şekil 3. Çalışmada elde edilen OÖK ve diğer il gruplarının ülke genelindeki dağıımları.

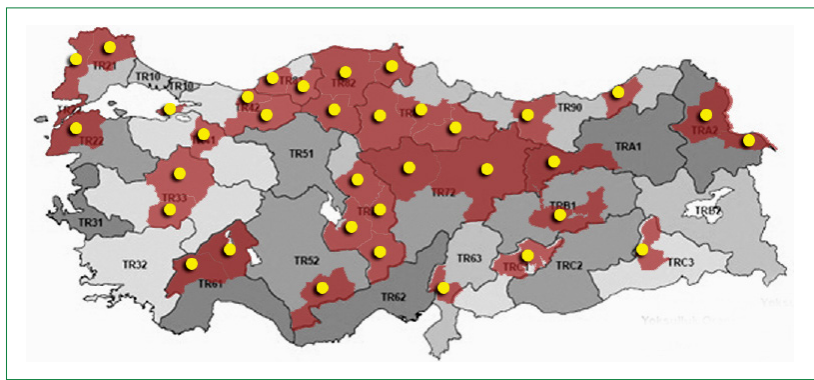

Şekil 4. Çalışmada elde edilen OÖK'lerin Düzey 2 Bölgeleri bakımından coğrafi dağııımları

I). Doğu ve Güneydoğu Anadolu bölgelerinin, OÖK temsiliyeti en düşük bölgeler olmasında, bu bölgelerde son yıllarda göçe bağlı nüfus artışları sonucu büyükşehir olan illerin (Mardin, Van) genel nüfus aralığı dışında kalmasının payı önemlidir (Şekil 3). Belirlenen OÖK’ler, tarımda en büyük işgücüne sahip il kümesi olurken, sanayi ve hizmet sektörlerinde ülke ortalamalarına çok yakın değerlere sahiptirler. Ayrıca IGE ve işgücüne katılım düzeyi bakımından ülke ortalamalarının üzerinde olmaları, gelişme dinamikleri bakımından umut vericidir (Tablo 10). OÇK'lerin çevre performansı bakımından ülke ortalamasının altında kalmasında, gelişme düzeyleri itibariyle kullanılan enerji türleri, atık yönetimi ve kirletici/eski tür sanayi alanlarının varlığı gibi nedenleri sıralamak mümkündür.

OÖK’lerin düzey 2 bölgeleri bakımından dağıımına bakıldığında, Orta-Kuzey Anadolu ve Trakya bölgelerinin en büyük temsil gücüne sahip oldukları; önemli büyükşehirlerin komşu bölgeleriyle güney kıyı kesiminin görece nüfus büyüklüğü ve gelişme düzeyleri bakımından OÖK’lerden ayrıştığı, doğu ve güneydoğuda yer alan bölgelerin bir kısmında hiç OÖK'in yer almadığı görülmektedir (Şekil 4). Diğer yandan TR8I, TR82 ve TRA2 bölgelerinde Kalkınma Ajansları'nın kurulduğu öncü kentlerin OÖK oldukları (sırasıyla Zonguldak, Kastamonu ve Kars) tespit edilmiştir.

OÖK'lere, bu çalışmanın ortaya koymaya çalıştığı çözüm yaklaşımının temel niteliği (dinamikleri) üzerinden daha ilişkisel bakabilmek için Tablo Il'deki kavramsal ayrıma gidilmiştir. Burada çalışmanın başında belirtilen iki temel boyut olan kırkent ilişkileri ile dayanışma ve ağ ilişkileri boyutları dışında bu boyutlarla yakından ilişkili olan genel gelişmişlik ile ekoloji-sürdürülebilirlik boyutları da dikkate alınmıştır. Her bir boyutu hangi OÖK'lerin daha güçlü temsil edebildiğini ortaya koyabilmek için öncelikle her bir boyutla yakından ilgili olan kriterler belirlenmiştir (Tablo II). Daha sonra da bu kriterler bağlamında temsil düzeyini güçlendirmek için belirli eşikler dikkate alınarak OÖK kümesi yeniden değerlendirilmiştir.

Daha sonra her bir boyut için belirlenen seçim koşuluna uyan OÖK’ler sıralanarak aşağıdaki Tablo 12 elde edilmiştir. 35 ilden oluşan OÖK kümesi söz konusu koşullarla tanımlanan temel boyutlara indirgendiğinde 25 il tabloya girebilmiş ve görece güçlü OÖK kümesini ortaya çıkarmıştır. Bu illerden 5'i her bir boyutta da yer alırken, 4'ü üç boyutta ve 3'ü de iki boyut içinde yer almışlardır. 13 il ise söz konusu boyutlara dayalı koşullu sıralamada sadece tek bir boyutun temsiliyetinde yer alabilmişlerdir (Tablo 12).

Farklı boyutlara dayalı bu tabloda yer alan OÖK'lerin mekânsal dağılımı ve diğer OÖK’ler ile olan ilişkisine bakıldığında herhangi bir kümelenmenin olmadığı, mekânsal açıdan birbirinden ayrık bir desen olduğu görülmektedir (Şekil 5). Bu durum farklı boyutlarda aynı anda yer alan tüm iller için geçerli olup, mekânsal açıdan farklı bölgelere dağılmış bu yapı 


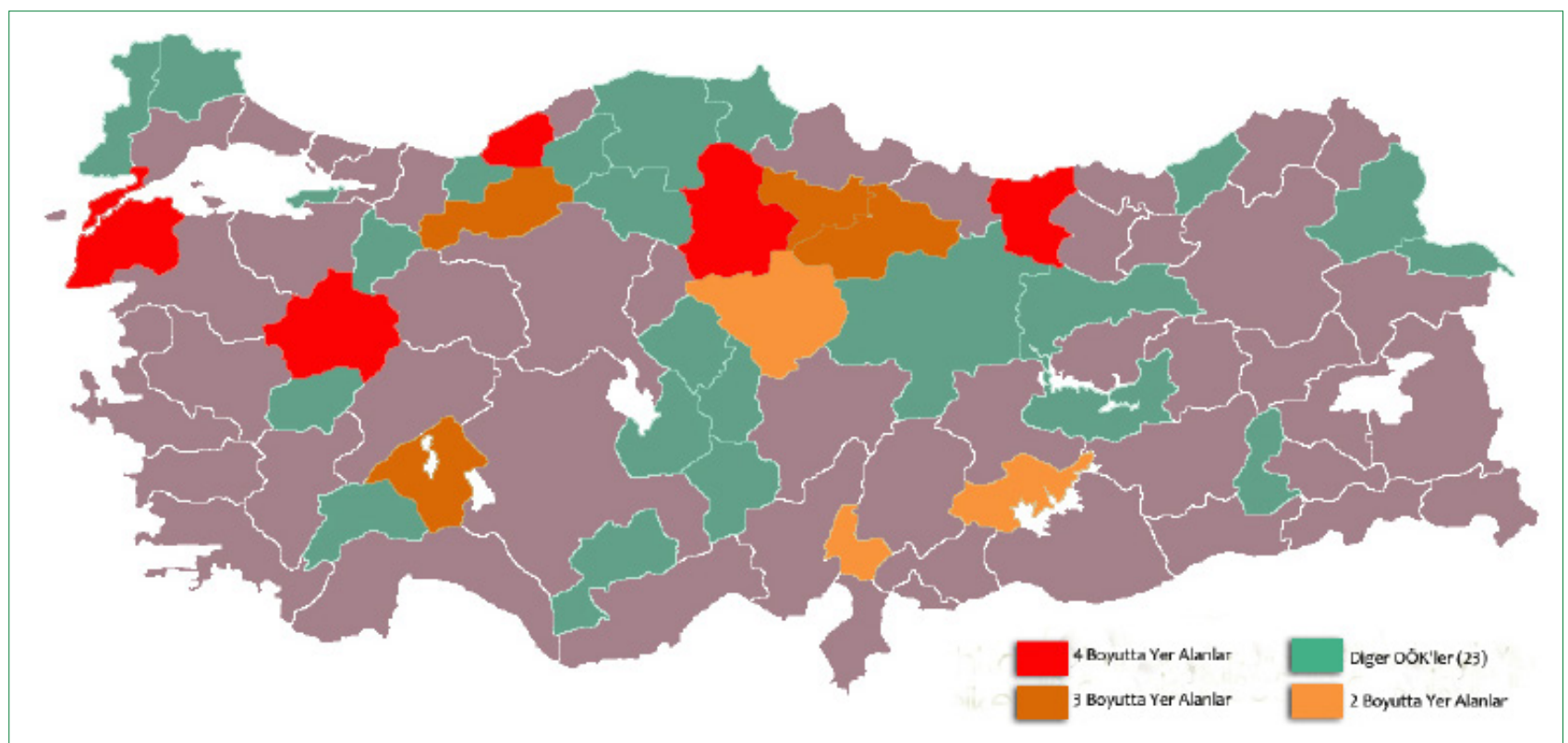

Şekil 5. OÖK’lerin 4 temel boyut üzerinden belirli koşulları sağlayabilenlerinin coğrafi dağlımları (Tek bir boyutu temsil eden I3 OÖK ve bu çok boyutlu temsiliyette yer alamayan 10 OÖK “Diğer OÖK’ler” grubu altında haritada gösterilmiştir).

OÖK’ler düzeyinde çok merkezli bir gelişme için elverişli bir altyapıyı temsil etmektedir. Bu çok merkezlilik aynı zamanda çok işlevlik anlamını taşımakta ve çözüm yaklaşımının farklı boyutlarının öncü coğrafyalarını ortaya koymaktadır.

\section{Sonuç ve Değerlendirme}

Dünya ve Türkiye kentleşmesinin izlediği yol, yakın gelecekte OÖK’lerin öneminin ve bu yerleşmelerin kentleşme sürecindeki rolünün artacağını gösterirken, diğer yandan kutuplaşan kentleşmeye (metropolleşmeye) dayalı sorunları daha fazla hissedeceğimizi ve bunun da başta daha güçlü ve rekabetçi/yarışmacı kentleşmenin zararlarından sakınan bir kır-kent ilişkisini/dayanışmasını öne çıkarabileceğini işaret etmektedir. Kentleşmenin yeni bir kavramsallığa duyduğu ihtiyacı konu alan tartışmalarda öne çıkan ağ ilişkilerinin de bu bağlamda dikkate alınması artık bir gereklilik halini almıştır. Kapsamıyla bu konuları dikkate alan bu çalışmada, Türkiye kentleşmesinin çok boyutlu sürdürülemezliğinden hareketle yeni bir yol arayışı için OÖK'ler üzerinden bir çözüm yaklaşımı geliştirilmeye çalışıımış ve bu anlamda kır-kent dayanışmasına ve ağ ilişkilerine uyumlu bir kavramsal çerçeve çizilerek buna uygun bir Türkiye OÖK kümesine ulaşılmıştır. Çalışma, içerdiği nüfusa dayalı ölçütler ve sınırlamalar bakımından diğer öncü çalışmalarla benzeşmektedir. Hedeflediği çözüm yaklaşımı bakımından diğer geçmiş çalışmalardan ayrışırken yöntemin son adımında kullanılan ölçütler, çalışmanın özgün yanını güçlendirmiştir. Çözüm yaklaşımında, kır-kent ilişkisinin ağ ilişkilerine dayalı yapısının yatayda ve karşılıklı üstünlüklerin paylaşılmasına dayalı bir dayanışmacı ilişki biçimini temsil edebilmesi ve bunun yerel ekonomileri olumlu yönde etkilemesi konusunda yöntem adımlarının OÖK'leri bu yönde daha açılkayıcı bir şekilde ortaya koyması sağlanmıştır. Ancak

Tablo I I. OÖK'lerin kavramsal analizinde dikkate alınan 4 boyuta dair kriterlerin dağılımı ve seçim koşulları

\begin{tabular}{|c|c|c|c|c|c|c|c|}
\hline \multicolumn{2}{|c|}{ GENEL GELişMişL iK } & \multicolumn{2}{|l|}{ KIR-KENT iLişKiLERi } & \multicolumn{2}{|c|}{ EKOLOJi-SŌRDŌRŌLEBILiRL IK } & \multicolumn{2}{|c|}{ DAYANIŞME VE AĞ iL iş̧KiLERi } \\
\hline Kriter & $\begin{array}{l}\text { Seçim } \\
\text { Koģulu }\end{array}$ & Kriter & $\begin{array}{l}\text { Seçim } \\
\text { Koşulu }\end{array}$ & Kriter & $\begin{array}{l}\text { Seçim } \\
\text { Koşulu }\end{array}$ & & \begin{tabular}{|l} 
Seçim \\
Koşulu
\end{tabular} \\
\hline IGE Grubu & 1,2 veya 3 & Kursal Nüfus Oranı & $\approx \% 25$ & $\begin{array}{l}\text { Çevre Performansı } \\
\text { Endeksi }\end{array}$ & 20,60 & $\begin{array}{l}\text { Ulusal Pazara } \\
\text { Erişilebilirlik Endeksi }\end{array}$ & $\approx 2$ \\
\hline Kentsel Nüfus Oranı & $=\% 50$ & Tarım Ișgücũ Oranı & $\approx \% 25$ & Kırsal Nüfus Oranı & $2 \% 25$ & $\begin{array}{l}\text { Genișbant Internet } \\
\text { Abone Indeksi }\end{array}$ & $\approx 550$ \\
\hline $\begin{array}{l}\text { Iş̦güicine Katılma } \\
\text { Oranı }\end{array}$ & $z \% 40$ & $\begin{array}{l}1000 \text { kiģi başına dùşen Tarıms al } \\
\text { Oretimle iliş kali Kooperatif Sayısı }\end{array}$ & $\approx 5$ & & & $\begin{array}{l}1000 \text { kişi başın a düş̧en } \\
\text { Tarıms al Oretimle ilişkili } \\
\text { Kooperatif Sayısı }\end{array}$ & $\approx 5$ \\
\hline $\begin{array}{l}\text { Ulusal Pazara } \\
\text { ErișilebilirlikEndeksi }\end{array}$ & $\geq 2$ & Çeure Performansı Endeksi & $\geq 0,60$ & & & & \\
\hline Hizmet işgücü Oranı & $\approx \% 30$ & $\begin{array}{l}\text { Ulusal Pazara Erişile bili rlik } \\
\text { Endeksı }\end{array}$ & $=2$ & & & & \\
\hline Sanay işoucu Oranı & $\approx \% 15$ & & & & & & \\
\hline
\end{tabular}


Tablo I2. Dört temel boyut üzerinden belirlenen seçim koşullarına uyan OÖK'lerin dağılımı (4 boyutta da yer alan iller kırmızı, 3 boyutta yer alan iller kahverengi, 2 boyutta yer alan iller açık kahverengi ve tek boyutta yer alan illerse en açık kahverengi ile gösterilmiştir.)

\begin{tabular}{|c|c|c|c|}
\hline $\begin{array}{l}\text { GENEL } \\
\text { GELIŞMIŞLIK }\end{array}$ & $\begin{array}{l}\text { KIR-KENT } \\
\text { ILIŞKILERI }\end{array}$ & $\begin{array}{c}\text { EKOLOJl- } \\
\text { SORDOROLEBILIRLIK }\end{array}$ & $\begin{array}{l}\text { DAYANIŞME VE } \\
\text { AG ILIŞKILERI }\end{array}$ \\
\hline Çanakkale & Çanakkale & Çanakkale & Çanakkale \\
\hline Çorum & Çorum & Çorum & Çorum \\
\hline Giresun & Giresun & Giresun & Giresun \\
\hline Kütahya & Kütahya & Kütahya & Kütahya \\
\hline Zonguldak & Zonguldak & Zonguldak & Zonguldak \\
\hline Tokat & Amasya & Amasya & Amasya \\
\hline Adıyaman & Bolu & Bolu & Bolu \\
\hline Osmaniye & Isparta & Isparta & Isparta \\
\hline Yozgat & Tokat & Tokat & Adıyaman \\
\hline Aksaray & & Burdur & Osmaniye \\
\hline Elazığ & & Çankırı & Yozgat \\
\hline Niğde & & Karaman & Nevşehir \\
\hline Sivas & & Kastamonu & Düzce \\
\hline \multirow[t]{4}{*}{ Uşak } & & Kırklareli & \\
\hline & & Rize & \\
\hline & & Sinop & \\
\hline & & Yalova & \\
\hline
\end{tabular}

il düzeyinde ihtiyaç duyulan 'aracısız ve ticari ağlar üzerinden yürütülen ekonomik faaliyetler', 'kentsel tarım', 'yerele özgü ticari örgütlenmeler', 'küçük aile çiftçiliği' 'belirli fon ve hibe mekanizmaları' ile 'yerel girişimcilik düzeyi' vb konularda dayanışmacı etkilerin ölçülebilirliği ve ağ potansiyelleri dolaylı olarak değerlendirilebilmiştir. Diğer yandan ağ ilişkilerinde çevrimiçi (online) iletişim altyapıları ve kullanıcı profillerini, bunların yerel ekonomi ile ilişkilerini kurma adına da aynı sorunla karşılaşılmıştır. Bu bakımdan ayrıntılı bir saha araştırması ya da daraltılmış bir örneklem üzerinden gerekli görülebilecek özgün ölçütlerin geliştirmesi mümkündür. Ayrıca ulusal ölçekte OÖK tablosunda yer alan değişkenlere dayalı 'panel data seti'nin (her yıl yeniden düzenlenen) olmayışı, iller arasındaki yakınsamalar ve eğilimlerin bütüncül bir şekilde irdelenmesini zorlaştırmaktadır.

Çalışmada yerleşme türleri bakımından ortaya çıkarılan nihai tablo, OÖK'ler üzerinden uygulamaya dayalı çeşitli politikalar geliştirilebilmesi için farklı kriterlerin ağırlıklı olarak temsil edilebildiği mekânsal alt kümeler için bir altyapı sağlamıştır. Burada ortaya çıkarılan 4 temel boyut bağlamında OÖK'lerle ilgili dayanışma ve ağ ilişkilerinin geliştirilebileceği bir yerleşmeler sistemi ve ekonomik yapı için en güçlü OÖK adaylarının hangileri olabileceği tespit edilmiştir. Öte yandan yöntem içindeki çoklu kriterlerin temsil düzeyi arttıkça, o illerdeki dayanışmacı kır-kent ilişkilerinin ağlar üzerinden sosyo-ekonomik bir gelişmeyi sağlaması da o derece kolaylaşacaktır. Çalışmada belirlenen OÖK kümesi, benzer çalışmalardaki bulgularla karşılaştırıldığında aşağıdaki çıkarımlara ulaşıımıştır:

- Yazar'ın (2006), 100.000-300.000 kent nüfusu aralığındaki, sosyo-ekonomik gelişmişlik düzeyine de bakılarak 5 gruba (I en gelişmiş) ayırdığı OÖK’lerden 3. ve 4. gruptaki kent- lerin, bu çalışmadaki OÖK’ler ile benzer profillere sahip oldukları görülmüştür.

- Öğdül vd'nin (2007) Yazar ile aynı dönemde yaptıkları çalışmalarında kırsallığı baskın olan bir Türkiye varken, bu çalışmadaki tespitler artık bunun yerini kır-kent arası geçiş niteliğindeki yerleşmelerin almaya başladığını ve bunda OÖK'lerin belirgin bir paya sahip olduğunu ortaya koymaktadır. Bu sonuç, ülkenin geçmişe göre daha dinamik bir süreç içinde olduğunu gösterirken, bunun OÖK’ler üzerinden kurulan çözüm yaklaşımları ve özellikle de kırkent dayanışması için olumlu bir temel oluşturacağı açıktır.

- Türkiye'nin Bölgesel Gelişme Ulusal Stratejisi'ndeki (Kalkınma Bakanlığı, 20ı5) yerleşim alanları sınıflandırmasındaki "Yapısal Dönüşüm İlleri, Bölgesel Çekim Merkezleri ve Öncelikli Gelişme İlleri grubunun bu çalışmada belirlenen OÖK kümesiyle önemli paralellikler gösterdiği tespit edilmiştir. Özellikle Yapısal Dönüşüm İlleri, sahip oldukları orta gelişmişlik düzeyi, sanayi açısından belirli düzeyde altyapıya sahip olup, ancak bu potansiyeli daha ileri düzeye taşıyabilmek için yapısal bir dönüşüme ihtiyaç duyan, çeşitlilik yönü düşük bir ekonomik yapıya sahip, tarım ve doğal kaynaklara dayalı ekonomilerin önemli olduğu, turizm alanındaki potansiyelini açığa çıkarması beklenen orta düzeydeki gelişmiş iller olarak tanımlanmakta ve bu çalışmadaki OÖK'lerin nitelikleriyle benzeşmektedir.

- Ayrıca bu çalışmada ortaya koyulan çözüm yaklaşımı, metropolleşmeye dayalı sorunların odağı halindeki İstanbul'un I//00.000 ölçekli -meri- Çevre Düzeni Planı'nda yer verilen OÖK odaklı çözüm politikalarıyla paralellikler içermekte ve çıkış noktası olan kentleşmeye dayalı sorunlar bağlamında birbirini tamamlayıcı nitelik göstermektedir.

Yakın gelecekte, sürdürülebilir bir kentleşme ve yerleşme gelişimi için daha sağlıklı ve uzun ömürlü bir kentleşme yaklaşımına ve bunun önemli bir parçası olan kırsal/ekolojik çevreye daha çok ihtiyacımız olacağı öngörülürken, kentsel nüfusun büyük bir kısmını barındıracak OÖK'in hem kentsel politikalar, hem de planlama yaklaşımları bakımından kayıtsız kalınamayacak bir yerleşme ölçeği olduğu artık tartışma götürmez bir gerçekliktir. Bu noktada önemli olan daha iyi bir kentleşme yaklaşımının ve bunu destekleyecek bir planlama altyapısının sağlanabilmesidir. Söz konusu çalışma, bu anlamda önemli bir yaklaşım ve çerçeve ortaya koyarak, geleceğin kentleşme ve planlama yaklaşımları için mevcut eğilimlerin ve niteliksel altyapıların yetersizliğini ortaya koyarken, ne gibi revizyonların ve paradigma değişimlerinin yapılması gerektiği konusunda mevcut yerleşme sistemimizde olmayan ancak eksikliği hissedilen OÖK'leri farklı nitelikleri ile ön plana çıkarmaktadır. Böylece bu kentlerin, hangi tür yerel ekonomiler üzerinden dayanışmacı ilişki ağları kurabilecekleri veya geliştirebilecekleri konusunda saha odaklı yeni alt çalışmalara ihtiyaç olacağı kabulü için önemli bir ön çalışma zeminin kurulduğu söylenebilir. 


\section{KAYNAKLAR}

A Summary of the Rochester Conversation on Mid-Size Cities, November 2002.

A World Of Cities, UN, 2014c.

Akturan U. ve Oğuztimur, S. 2016. Kent Markalaşması Kavramının İçeriğ ve Gelişimi: Farklı Disiplinler Farklı Yaklaşımlar. Planlama Dergisi. DOI: 10.14744/planlama.2016.76376.

Albert, M. (2007). Kapitalizmin Ötesinde Yaşam-Umudu Gerçeğe Dönüştürmek.

Altınok, E. \& Enlil, Z. (2012). Mekânın Yeniden Organizasyonunun Ekonomi Politiği.

Aysu, A.. (2013). Küresel Kapitalizme Koşut Olarak Türkiye Tarımında Değişim, Dönüşüm, Kırsal Planlama Üzerine Tartışmalar. MSGSÜ

Aysu, A.. (2015). Gıda Krizi-Tarım, Ekoloji ve Egemenlik: Metis.

Azadi, H. \& Ho, P. (2011). Agricultural land conversion drivers: A comparison between less developed, developing and developed countries.

Bilgi Teknolojileri ve İletişim Kurumu (BTK), 2017. Elektronik Haberleşme Sektörüne İlişkin Sektörel İl Bazında Yıllık İstatistik Bülteni. Sektörel Araştırma ve Strateji Geliştirme Dairesi Başkanlığı, Ankara.

Bolay, J. C. and Rabinovich, A. (2004). Intermediate cities in Latin America risk and opportunities of coherent urban development in cities.

Byerlee, D., Janvry, A. \& Sadoulet, E. (2009). Agriculture for Development: Toward a New Paradigm.

Cihanger, D., 2014. Çağdaş Şehircilik Paradigmasında Kent ve Kır:Yeni Bir Mekansal Temsil Biçimine Doğru. 8 Kasım Dünya Şehircilik Günü 38. Kolokyumu-Kentlerin Geleceği İstanbul: ŞPO .

Cities And The New Climate Economy: The Transformative Role Of Global Urban Growth, UN, 2014.

Copus, A., 2014. New Relationships Between Rural and Urban Areas In Eu Countries the James Hutton Institute, Aberdeen, 2015.

Çabuk, S. ve Demir, K. 2010. Türkiye'de Metropoliten Kentlerin Nüfus Gelişimi. Sosyal Bilimler Enstitüsü Dergisi Sayı: 28 Y1l: 2010/1 (193-215 s.)

Çalışkan, Ç., Çılgın, K., Dündar, U. \& Yalçıntan, M. C.. (2013). İstanbul Dönüşüm Coğrafyası, 3. Kentsel ve Bölgesel Araştırmalar Sempozyumu. Ankara.

Çavuşoğlu, E. (2017). Türkiye Kentleşmesinin Toplumsal Arkeolojisi: Ayrıntı Davis, M. (2010). Gecekondu Gezegeni: Metis.

Erkan, N. E., 2007. Dünyanın Yerel Aynası. Ayşegül Mengi, (Ed.). Kent ve Politika-Antik Kentten Dünya Kentine içinde. İstanbul: İmge.

Erkut G. \& Özgen C. (2013). Avrupa Bölgesel Politikaları ve Kırsal Alanlar, Kırsal Planlama Üzerine Tartışmalar, MSGSÜ.

European Planning Studies, 18: 9, 1519 - 1541.

Fulton, W. 2002. The Mid-size City: Exploring Its Unique Place in Urban Policy. A Summary of the Rochester Conversation on Mid-Size Cities, November.

Gıda Tarım ve Hayvancılık Bakanlığı (Koordinatör), Kalkınma Bakanlığı, Çevre ve Şehircilik Bakanlığı, AB Bakanlığı, TÜİK, İçişleri Bakanlığı, Maliye Bakanlığı, Hazine Müsteşarlığı İşbirliği ile, 2014. Ulusal Kırsal Kalkınma Stratejisi - 2014-2020, Ankara.

Gülçubuk, B. (2018). Kırsal Kalkınma Politika ve Uygulamalarında Öncelik Arayışları ve Türkiye Açısından Değerlendirme. Faik Gür ve Murat Bayramoğlu (Der.), Sürdürülebilir Yaşam Penceresinden Yerel ve Kırsal Kalkınma içinde, İstanbul: Özyeğin Üniversitesi.

Gülümser, A. A. (2010). Kırsalı Yeniden Okumak: Yaratıcı Kapasite ve Sıcak Nokta Teorisi.

Gülümser, A. A., Levent, T. B. \& Nijkamp J. (2010a). Türkiyénin kırsal yapısı: $\mathrm{AB}$ düzeyinde bir karşılaştırma.

Gümrük ve Ticaret Bakanlığı (GTB), 2018. Türkiye’de İller Bazında Tarımsal Üretime Dayalı Kooperatif ve Ortak Sayıları Dökümü. Kooperatifçilik Genel Müdürlüğü, Ankara.

Güney, M. \& Selçuk, E. (2012). Tarım Ülkesi Olan Türkiyénin Kentleșme Seyri: Yasaların Oluşturduğu Kent, 3. Kentsel ve Bölgesel Araştırmalar Sempozyumu: Ankara.

Güney, M., E., \& Selçuk, İ., A. (2012). Tarım Ülkesi Olan Türkiyénin Kentleşme Seyri: Yasaların Oluşturduğu Kent, 3. Kentsel ve Bölgesel Araştırmalar Sempozyumu, Ankara.

Harvey, D. (2013). Asi Şehirler: Metis.
Hildreth, P. 2007. Understanding medium-sized cities. Town \& Country Planning.

İrdem, İ. \& Mutlu, A. (2016). 6360 Sayılı Yasayla “Kır-Kent” Kavramlarının Muğlâklaşması Sorunu ve Olası Sonuçları.

İstanbul Büyükşehir Belediyesi (İBB), 2009. 1/100.000 Ölçekli İstanbul Çevre Düzeni Planı Açıklama Raporu, İstanbul.

Janvry, A. De, (2010). Agriculture for development: new paradigm and options for success, International Association of Agricultural Economists.

Johnson, T. vd. 2016. Thef Impact of Urban Growth on Agricultural and Rural Non-farm Growth in Kenya.

Kalkınma Bakanlığı, (2015). Türkiye Bölgesel Gelişme Ulusal Stratejisi (2014-2023). Ankara.

Kalkınma Bakanlığı, 1963-2014. Türkiye I., II., III., IV., V., VI., VII., VIII., IX. ve X. Ulusal Kalkınma Planları, Ankara.

Karabey, H. (2014). Direnen İstanbul: Ayrıntı.

Keyder, Ç. \& Yenal, Z. (2014). Bildiğimiz Tarımın Sonu: Küresel İktidar ve Köylülük: İletişim.

Kiper, P., 2007. Küreselleşme Sürecinde Değișen Kentler-Yitirilen Değerler. Ayşegül Mengi, (Ed.). Kent ve Politika-Antik Kentten Dünya Kentine içinde. İstanbul: İmge.

Klaus R. Kunzmann, Medium-sized Towns, Strategic Planning and Creative Governance in the South Baltic Arc, 2013.

Kraus, S. (2013). A Call for New Ruralism: Reinvestment in Metro-Region Agriculture Is Integral to Metro-Region Sustainability.

Leeuwen, E. van. (2015). Urban-Rural Synergies: An Explorative Study at the NUTS3 Level.

Lefebvre, H. (1970). Kentsel Devrim: Sel.

Léo, P., Philippe, J. \& Monnoyer, M-J. (2009). Services and high skills: a new challenge for developing medium-sized cities.

Mkhize B., Johnson, T., Samboko \& You L. (2016). The Impact of Urban Growth on Agricultural and Rural Non-farm Growth in Kenya.

OECD, (2011). Regional Typology Report. Directorate for Public Governance and Territorial Development.

Our Urbanizing World, No:2014/3, UN, 2014a.

Öğdül, H. (2010). Urban and Rural Definitions in Regional Context: A Case Study on Turkey.

Özpınar, E. \& Koyuncu, E. (2016). Türkiyéde İnsani Gelişmişlik İller Arasında Nasıl Farklılaşıyor? 81 İl İçin İnsani Gelişmişlik Endeksi. TEPAV.

Özyakışır, D., 2012. İç Göç Hareketleri ve Geriye (Tersine) Göçün Belirleyicileri: TRA 2 Bölgesinden (Ağrı, Kars, Iğdır, Ardahan) İstanbul'a Gerçekleșen Göç Üzerine Bir Saha Araştırması. Doktora Tezi, Erzurum Atatürk Üniversitesi Sosyal Bilimler Enstitüsü İktisat Ana Bilim Dalı.

Pizzoli E. \& Gong X. (2007). How to Best Classify Rural and Urban?

Reader J. (2007). Şehirler: Yapı Kredi Yayınları.

Sassen, S. (2012). http://www.scenariomagazine.com/why-mediumsized-cities-will-prevail-in-the-future/ Edit: Sally Khallash. Er.Tarihi: 23.09.2017.

Sevinç, K. 2012. Kentsel Mekanın İnsan Psikolojisi Üzerine Etkileri. Türkiye Lisansüstü Çalışmalar Kongresi, İlmi Etüdler Derneği (İLEM).

Small and medium sized towns in their functional territorial context, ESPON, 2013.

Şen, M., 2014. Türkiye’de İç Göçlerin Neden ve Sonuç Kapsamında İncelenmesi. Çalışma ve Toplum, 2014/1.

Şimşek, A. (2015). Erişilebilir Şehirler ve Bölgeler: Erişilebilirliğin Bölgesel Kalkınmaya Etkisi ve İller Bazında Erişilebilirlik Endeksinin Geliştirilmesi, Kalkınma Bakanlığı: Ankara.

TATLI, S. 2016. Mekansal Ekonometrik Modeller ve Türkiye’de İç Göçün Belirleyicilerinin Analizi. YL Tezi, İstanbul. İstanbul Üniversitesi Sosyal Bilimler Enstitüsü Ekonometri Anabilim Dalı.

Tekeli, İ. (2011). Kent, Kentli Hakları, Kentleşme ve Kentsel Dönüşüm: Tarih Vakfi.

Tekeli, İ. (2016). Yerleşmeler İçin Temsil Sorunları: İdealkent.

Tekeli, İ., Eraydın, A., Berkman, G., ŞENGÜL, T. \& Babalık, E. (2006). Yerleşme Bilimi/Çalışmaları İçin Öngörüler, Türkiye Bilimler Akademisi Raporları, Ankara.

The World's Cities in 2016, Data Booklet, UN, 2016a.

Tokuçuoğlu, B. (1993). Çevre Sorunları ve Kentleşme, Çevre Dergisi, Sayı:6. TÜİK. (1927-2000). Türkiye İl Nüfus Sayımı Sonuçları, Ankara. 
TÜİK. (2007-2017). Adrese Dayalı Nüfus Kayıt Sistemi İstatistikleri, Ankara.

TÜİK. (2013). Türkiye Yaşam Memnuniyeti Araştırması, Ankara.

TÜIK. (2017). Kır / Kent Tanımının Revizyonu Bülteni: http://www.resmiistatistik.gov.tr Er. Tarihi: 25.09.2017.

TÜİK. İllerde Yaşam Endeksi-2015, 2016, Ankara.

Urbanization and Development: Emerging Futures, World Cities Report, UN, 2016b.

World Urbanization Prospects (Highlights), UN, 2014b.

Yakar, M. 2013. Türkiyéde İller Arası Net Göçlerle Sosyo-Ekonomik Gelişmişlik Arasındaki İlişkinin Coğrafı Ağırlıklı Regresyon ile Analizi. Ege Coğrafya Dergisi, 22/1, 27-43, İzmir.

Yaşar, C. G., (2013). Bütünșehir'de Görünmez Kır ve Topyekun Kentleșme Afeti: Büyükşehirlerde Kentsel Büyüme ve Tarım. 8 Kasım Dünya Şehircilik Günü 37. Kolokyumu-Kent Yönetimi ve Planlama. İzmir: ŞPO.

Yaşlak, B., 2016. Onlıne Entrepreneurshıp as a Strategy For Rural Development: Case Of Turkey. Department of Urban and Regional Planning Regional Planning Programme, ITU.

Yazar, K. (2006) Sürdürülebilir Kentsel Gelişme Çerçevesinde Orta Ölçekli Kentlere Dönük Kent Planlama Yöntem Önerisi, Doktora Tezi, Ankara, 2006.

Yoloğlu, A. C., (2017). Kitap İnceleme: İlhan Tekelínin "Dünyáda ve Türkiye'de Kent-Kır Karşıtlığ Yok Olurken Yerleşmeler İçin Temsil Sorunları ve Strateji Önerileri” Başlıklı Çalışması. Planlama Dergisi.

Živanović, Z., Tošić, B. \& Krevs, M. (2014). Multıple-Criterı Analysıs As A Method For Defining Mediumsızed Citıes: The Example Of Central Serbia.

442 Sayıl1 Köy Kanunu, http://www.mevzuat.gov.tr/MevzuatMetin/1.3.442. pdf.

5216 Say1l Büyükșehir Belediyesi Kanunu, http://www.mevzuat.gov.tr/MevzuatMetin/1.5.5216.pdf.

6360 Sayılı On Dört İlde Büyükșehir Belediyesi ve Yirmi Yedi İlçe Kurulması İle Bazı Kanun ve Kanun Hükmünde Kararnamelerde Değisşiklik Yapılmasina Dair Kanun, 2012.

9. UKP Özel İhtisas Komisyonu Raporları-Çevre ve Yerleşmeler, 2007,

9. Ulusal Kalkınma Planı-Çevre ve Yerleşmeler Özel İhtisas Komisyonu Raporu, DPT, Ankara, 2007.

\section{INTERNET KAYNAKLARI}

http://ec.europa.eu/eurostat/statistics-explained/index.php/ Glossary:Urban-rural_typology Er. Tarihi: 20.10.2017.

http://data.worldbank.org/indicator, Dünya Bankası, Er.Tarihi: 21.10.2017 http://www.tuik.gov.tr/PreHaberBultenleri.do?id=15844 (TÜIK, 2017a, Nüfus Projeksiyonlar1, 2013-2075) Er. Tarihi: 20.01.2018.

https://data.oecd.org/popregion/urban-population-by-city-size.htm Er. Tarihi: 20.01.2018.

www.smart-cities.eu Er. Tarihi: 20.11.2017.

https://tez.yok.gov.tr/UlusalTezMerkezi Er. Tarihi: 20.01.2018.

http://www.resmiistatistik.gov.tr/?q=tr/content/18-k\%C4\%B1rkenttan\%C4\%B1m\%C4\%B1n\%C4\%B1n-revizyonu Er. Tarihi: 25 Eylül 2017. 